\title{
Microambientes e conservação preventiva em áreas indoor: o caso do espaço interior não climatizado da Casa de Dona Yayá, em São Paulo (Brasil)'
}

Microenvironments and preventive conservation in indoor areas: the case of the non-climatised indoor area of Casa de Dona Yayá in São Paulo (Brazil)

\author{
ANDREA CAVICCHIOLI² \\ Universidade de São Paulo / São Paulo, SP, Brasil
}

\author{
PRISCILA LEITÃO DENARDI ALEGRE ${ }^{3}$ \\ Pinacoteca do Estado de São Paulo / São Paulo, SP, Brasil
}

\author{
ARIEL GUILGER SIMÕES MARTINS ${ }^{4}$ \\ Universidade de São Paulo / São Paulo, SP, Brasil
}

RESUMO: Neste artigo, buscou-se resgatar criticamente o histórico do processo de consolidação da noção de conservação preventiva de bens culturais materiais baseada em controle ambiental e expor uma síntese do estado da arte dos conhecimentos sobre a ação dos agentes ambientais nos processos de degradação física, química e biológica dos materiais que tipicamente compõem tais bens. A discussão, desenvolvida principalmente na perspectiva de recintos interiores de instituições envolvidas na preservação da cultura material, perpassou por uma reflexão sobre o conceito de microambientes e microclimas e sobre a conveniência de sua afirmação na abordagem do problema. Os temas tratados foram contextualizados mediante o estudo do caso específico das áreas interiores da Casa de Dona Yayá, em São Paulo, no qual foram apresentadas e debatidas algumas possibilidades de atuação no processo de caracterização dos espaços indoor, suas potencialidades e limitações.

PALAVRAS-CHAVE: Conservação preventiva. Ambientes interiores. Microambientes. Gestão ambiental.

\begin{abstract}
1. A elaboração deste artigo contou com o apoio de toda a equipe do CPC-USP e, em particular, a conservadora Cibele Monteiro da Silva, pela colaboração na pesquisa; da Pró-Reitoria de Cultura e Extensão da Universidade de São Paulo, pelo apoio financeiro com os recursos disponibilizados no âmbito dos editais de 2013 (Edital 7 - Preservação de Acervos Documentais, Memórias e Monumentos); e da Pró-Reitoria de Graduação da Universidade de São Paulo, pela concessão de bolsa de iniciação científica.

2. Bacharel (Università agli Studi di Milano), mestre (University of London) e doutor (Universidade de São Paulo) em química e professor associado da Escola de Artes, Ciência e Humanidades da Universidade de São Paulo (EACH-USP), atuando no curso de Gestão Ambiental e no programa de pós-graduação interdisciplinar em Sustentabilidade. E-mail: <andrecav@usp.br>.

3. Bacharela em Artes Visuais (Fundação Antônio Álvares Penteado, FAAP),
\end{abstract}


mestra em Mudança Social e Participação Política (USP) e restauradora na $\mathrm{Pi}$ nacoteca do Estado de São Paulo. E-mail: <palegre@ pinacoteca.org.br $>$.

4. Bacharelanda no curso de Gestão Ambiental (EACH-USP), desenvolveu projetos de iniciação científica ligados ao tema da conservação preventiva de bens culturais e impactos associados com processos de biodeterioração. E-mail: <ariel.guilger@ hotmail.com>.

5. Prefácio de Garry Thomson. Cf. May Cassar (1994, p. $\mathrm{x}$ ).
ABSTRACT: This paper makes a critical assessment of the historical consolidation process of the notion of preventive conservation of tangible cultural heritage based on environmental control. Within this aim, a summary of the state-of-the-art of the knowledge on the role of environmental factors in the physical, chemical and biological degradation of the materials that typically compose such artefacts is also presented. The discussion, focused on the perspective of indoor areas of institutions concerned with cultural preservation, encompassed a number of considerations on the concept of microenvironment and microclimate and on the adequacy of their assertion in the approach to the problem. The topics were contextualised through the specific case-study of the indoor areas of the historical building Casa da Dona Yayá (Sao Paulo, Brazil), in which some of the characterisation possibilities, their potentials and limitations, were highlighted and debated.

KEYWORDS: Preventive conservation. Indoor areas. Microenvironments. Environmental management.

\section{MICROAMBIENTES E CONSERVAÇÃO PREVENTIVA}

Historicamente, a ideia de concentrar esforços para a conservação de bens culturais materiais partindo do controle ambiental das áreas imediatamente circunstantes aos artefatos a serem protegidos tem como marco a publicação do livro de Garry Thomson The Museum Environment, em 1978 (seguido por uma segunda edição em 1986). Embora o material contido nessa publicação não seja original e o próprio autor aponte, no prefácio da primeira edição, que seu objetivo é sintetizar informações que até aquele momento circulavam de forma esparsa, o texto teve um papel central no processo que levou a firmar a questão da prevenção baseada no controle do ambiente como estratégia alternativa ao restauro na conservação:

After the Second World War there was much to be done in museum buildings in Europe. Unfortunately, for many years little consideration was given to improving the conservation of their contents. Restoration? Yes! Conservation? Oh yes, that was the same as restoration, was it not? 5

No trabalho, o autor fornece o arrazoado geral de como os diversos fatores ambientais atuam sobre os materiais e, apontando para a complexidade das questões envolvidas na abordagem prática ao problema, abre as portas para as pesquisas nessa área nos anos vindouros: 
We have a very uneven knowledge of how fast things in the museum change and what causes these changes, and yet we have to erect this framework of preventive conservation before rather than after our research has reached a dignified level of completion. ${ }^{6}$

Assim, em aproximadamente uma quinzena de anos, os diversos autores assumem o desafio lançado por Thomson e se debruçam sobre o efeito potencial de fatores físicos, como temperatura e umidade relativa lobjetos da revisão de Dario Camuffo em seu Microclimate for Cultural Heritage, ${ }^{7}$ rico de estudos de caso realizados principalmente na década de 1980), radiação luminosa (com destaque para os trabalhos de Feller, ${ }^{8}$ Michalski ${ }^{9}$ e Schaeffer ${ }^{10}$ ) e fatores químicos, ou seja, polventes atmosféricos. Sobre essa última temática, cabe mencionar os trabalhos fundamentais de Baer e Banks, "1 Peter Brimblecombe ${ }^{12}$ e, mais adiante, Jean Tétreault. ${ }^{13}$

Em 1994, no livro Environmental Management - Guidelines for Museums and Galleries, May Cassar afirma que:

The key to the survival of museum collections is a stable indoor environment and vital to this is a well-maintained building with effective environmental services. ${ }^{14}$

Nesse local, a preocupação com o controle ambiental é estendida à questão de como conseguir uma efetiva conciliação de preceitos teóricos e desafios práticos na gestão de espaços indoor.

Greater access to the collection improves public goodwill, raises museum's profile, and increases the sales from its shop - all of which contribute to the survival of the collection. ${ }^{15}$

Atenta às exigências de museus e galerias e ciente de seus diversos interesses e da necessidade à qual estão sujeitos, de garantir fisicamente a manutenção de uma infraestrutura de trabalho, a autora mostra como a minimização do risco de danos perpassa, ao mesmo tempo, por uma compreensão das bases físico-químicas do problema da estabilidade dos materiais, pelo conhecimento aprofundado das dinâmicas microclimáticas dos ambientes e também pela capacidade de implementar modelos de gestão do espaço e das pessoas envolvidas, que abracem todos os objetivos de um centro de conservação:

Preventive conservation management within museums has two distinct yet complementary aspects: the technical and the organizational. Technical information enables those who monitor and control the museum environment to work effectively, to create the physical environment that is of such fundamental importance to the survival of the collection. [...] But collections also exist within an institutional context. Problems with the physical environment of
6. Cf. Garry Thomson (1986, prefácio à $1^{\mathrm{a}}$ edição).

7. Ver Dario Camuffo (1998).

8. Ver Robert Feller (1994).

9. Ver Stefan Michalski (2001).

10. Ver Terry Schaeffer (2001).

11. Ver Norbert Sebastian Baer e Paul Banks (1985).

12. Ver Peter Brimblecombe (1990).

13. Ver Jean Tétreault (2003).

14. Cf. May Cassar (1994, p. $x i)$.

15. Cf. May Cassar (1994, p. 5). 
16. Cf. May Cassar (1994, p. 4).

17. Ver Jonathan Ashley-Smith (1999).

18. Ver Norbert Sebastian Baer (1989), Robert Waller (2002) e Stefan Michalski (2004).

19. Cf. Stefan Michalski (2004, p. 67-68). collections are better understood - and are certainly more likely to be resolved - if they are debated and discussed in the context of the institution's operational framework. ${ }^{16}$

Observe-se que, a essa altura (começo da década de 1990), a autora já mostra a incorporação da prática da conservação preventiva como a abordagem principal na políitica de proteção dos acervos e considera adquirido o fato de o controle ambiental constituir uma tarefa central de uma instituição como museu.

Numa linha de pensamento bastante parecida, Ashley-Smith ${ }^{17}$ preocupase com a definição de ferramentas de apoio à gestão partindo dos princípios da conservação preventiva. No seu caso, assim como outros autores, ${ }^{18}$ utilizase o conceito de risco de impacto, no qual se estima a gravidade de possíveis eventos deletérios para a estabilidade dos objetos e essa é ponderada em função da probabilidade de o evento ocorrer, chegando-se a uma apreciação numérica ou semiquantitativa do risco (risk assessment, por exemplo: risco baixo, médio ou elevadol que serve como instrumento para tomadas de decisões (decision making driven by risk management). O que interessa aqui é que essa abordagem também pressupõe aprofundar conhecimentos a respeito da ação de fatores ambientais sobre os materiais - discussão que, de fato, ocupa uma boa parte da monografia de Ashley-Smith.

Naquilo que poderia ser considerado uma aproximação ideal na gestão de coleções e espaços de conservação, as informações são analisadas em modelos que levam em consideração o funcionamento do sistema como um todo, numa visão holística da conservação, em que seja reduzido ao mínimo o espaço para ações individuais. Nessa mesma linha de raciocínio, Michalski observa que:

One then looks for options that address several risks at once. It may be more cost-effective to spend a little more on an option that solves several risks than to implement the lowest cost option of each risk. [...] The word integrated has recently emerged as another preservation management ideal. It means to bring an independent and isolated activity into the larger system. The goal is not just a grand theory, but a practical holistic operation. It is a relative term, inasmuch as some apply it to the integration of pest control within the museum operations, others propose it for all preservation activities within the museum. The challenge is this: an integrated method is a diffuse and system wide method that cuts across many independent museum activities. ${ }^{19}$

Claramente, trata-se aqui de uma situação que, na realidade, é abordada num grau tão elevado de sofisticação que talvez somente as grandes instituições tenham fôlego para desenvolver e sustentar. Entretanto, esses trabalhos podem ser enxergados, pelo menos, como uma inspiração para promover uma cultura de real e robusta sensibilidade sobre processos de degradação e fatores que influenciam 
sua taxa de ocorrência e de organização e planejamento das atividades de conservação que vão além da improvisação. Em particular, Michalski alerta para os perigos de pautar a gestão de ambientes interiores exclusivamente num espírito de bom senso e com práticas tidas como adequadas para a manutenção de residências comuns:

Many authors have noted that the strategies of traditional "good house-keeping" resemble good collection preservation. In other words, a lot of preservation is common sense. In fact, the "list of the basics" presented earlier would be very familiar to a housekeeper a hundred years ago. On the other hand, some habits of housekeeping can damage the museum collections. ${ }^{20}$

Esse processo pode também ser acompanhado pela ampliação da literatura científica focada nessas questões, dos investimentos das agências de fomento à pesquisa (notadamente no âmbito dos amplos guarda-chuvas dos chamados Framework Programmes da União Europeia, conforme a revisão de Chapuis et al.|, ${ }^{21}$ de redes de grupos e instituições de investigação científica e de fóruns de disseminação. Num primeiro momento, presencia-se a expansão de estudos centrados em estratégias de monitoramento dos fatores ambientais /sobretudo temperatura, radiação luminosa, umidade e outras espécies gasosas presentes na atmosfera), identificação de fontes e caracterização de dinâmicas espaciais e temporais. Mais adiante, as pesquisas avançam na direção dos mecanismos físicos e químicos de degradação provocados pelos fatores ambientais no intuito de aperfeiçoar a compreensão da contribuição de cada um deles no decaimento dos materiais, de reconhecer os processos de degradação por meio de sinais premonitórios, eventualmente microscópicos (early warning signs) e, evidentemente, de identificar ações de contenção ou remediação.

Nesse contexto, grande importância adquiriu a expansão de técnicas de diagnóstico e de caracterização química dos materiais presentes nos objetos de interesse histórico e artístico e seus produtos de degradação. Inovações foram conseguidas tanto pela melhora da capacidade de identificação qualitativa ou quantitativa quanto pela expansão da possibilidade de realizar as análises de forma não destrutiva e com dispositivos portáteis, o que ampliou enormemente as oportunidades de análise de artefatos cultuais, ajudando a entender melhor a resposta dos materiais aos estímulos provocados por fatores ambientais. Assim, muitas contribuições nessa direção são encontradas a partir de grupos de pesquisa ligados ao desenvolvimento de técnicas e instrumentação de espectroscopia vibracional ${ }^{22}$ e de análise elementar e morfológica de superfícies, ${ }^{23}$ ou ainda de laboratórios especializados em métodos tradicionais de separação e quantificação, ${ }^{24}$ termoanálise ${ }^{25}$ e eletroanálise. ${ }^{26}$
20. Cf. Stefan Michalski (2004, p. 66)

21. Ver Michel Chapuis, Adèle Lydon e Astrid Brandt-Grau (2009).

22. Ver Peter Vandenabeele, Howell Edwards e Jan Jehlocka (2014).

23. Ver René van Grieken e Koen Janssens (2005).

24. Ver Maria Perla Colombini et al. (2010) e Antonio Doménech-Carbó (2010).

25. Ver Marianne Odlyha (2003).

26. Ver Antonio Doménech-Carbó (2010). 
27. Ver Tim Padfield, David Erhard e Walter Hopwood (1982), Pamela Hatchfield (2002) e Alexandra Schieweck e Tunga Salthammer (2009).

28. Ver Susana López-Aparicio et al. (2010) e Terje Grøntoft et al. (2010).

29. Ver Robin Clark e Peter Gibbs (1998).
E, finalmente, um importante avanço ocorrido nas últimas décadas no quadro da conservação preventiva dos bens culturais diz respeito ao reconhecimento das diferentes dimensões espaciais que precisam ser consideradas para uma correta identificação dos fatores associados aos processos de degradação e à avaliação do risco para as coleções, pois, cada vez mais, as pesquisas vêm trazendo à tona a existência, nas áreas de conservação e em múltiplas escalas, de subzonas apresentando características ambientais específicas e potencialmente favoráveis a condições de risco de danos para os materiais. É nesse quadro que vai aparecendo todo um conjunto de investigações voltadas para a identificação, a delimitação e a caracterização de tais microambientes e seus respectivos microclimas (Figura 1).

Na prática, em alguns casos, o emprego da expressão microambientes se deu em alternativa a ambientes interiores (indoor environments), mas essa opção demonstra-se limitada. Primeiramente, porque o espaço em questão pode não ser necessariamente interno (in-doors), podendo, em tese, ser qualquer outra área de alguma forma delimitada que apresente características distintas do quadro geral do entorno [um jardim, possivelmente, pode ser considerado um microambiente com seu próprio microclima, sobretudo em termos de umidade, incidência de luz e presença de (micro-) organismos]. Mas, sobretudo, o conceito de microambiente se presta a ser adaptado a um conjunto de situações muito mais amplo, podendo abranger desde pequenas salas dentro de um museu até os filmes de espessuras micro ou nanométricas presentes nas superfícies dos materiais.

Especificamente, os microambientes de gabinetes de exposição, vitrines, caixas para o acondicionamento dos artefatos, gavetas e armários foram bastante estudados, sobretudo com relação à possibilidade de que o confinamento proporcione o acúmulo de substâncias gasosas liberadas pelos materiais do recipiente ou do próprio objeto conservado. ${ }^{27}$ Mais recentemente, a área interna das molduras de quadros foi detalhadamente investigada em estudos que mostraram se tratar de um microambiente bastante distinto em termos de concentração de polventes de origem externa e produzidos in situ, determinando, inclusive, condições de risco particularmente elevadas. ${ }^{28}$ Numa escala ainda mais reduzida, às vezes um microambiente é limitado às partes mais internas do objeto: as páginas de um livro; o lado menos exposto ao sol de uma estátua sujeita a agressão microbiológica; os túneis criados por insetos ou as fraturas numa parede; o interior de um instrumento musical. A esse respeito, é interessante lembrar o caso, descrito por Clark e Gibbs, ${ }^{29}$ no qual as páginas internas de antigos manuscritos se tornaram microambientes propícios à transformação química do pigmento branco de chumbo (carbonato básico de chumbo, usado para a coloração de imagens de anjos) em sulfeto de chumbo, resultando na coloração preta dos rostos, possivelmente rosada na origem. 

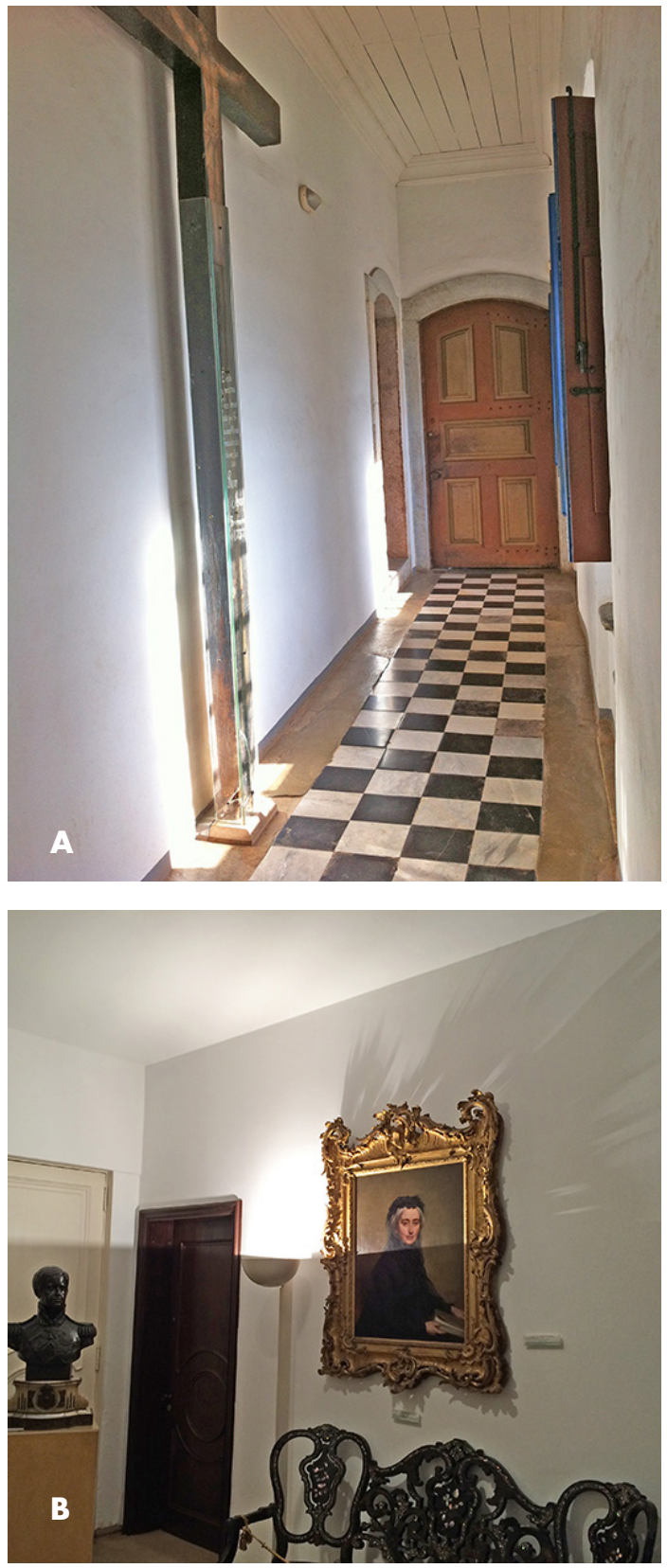
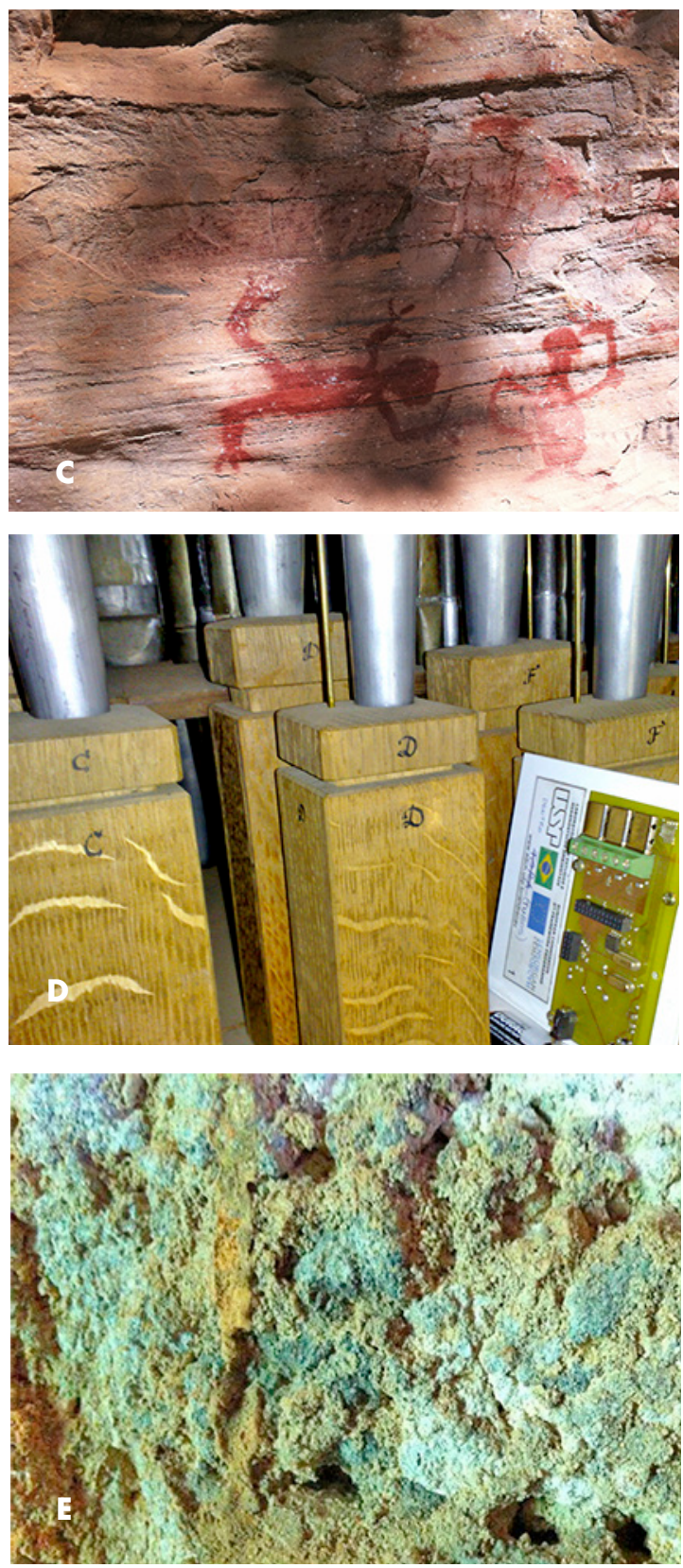

Figura 1 - Fotografias mostrando exemplos de microambientes em diferentes contextos e escalas espaciais. A: corredor lateral oeste da igreja do Santuário do Bom Jesus de Matosinhos (Congonhas, MG, novembro de 2013 ); B: área expositiva da Fundação Maria Luisa e Oscar Americano (São Paulo, SP, maio de 2015); C: pinturas rupestres em paredão rochoso ao ar livre na Serra do Cipó (Lagoa Santa, MG, novembro de 2013); D: sistema de monitoramento instalado no interior do órgão de tubos Arp Schnitger (Mariana, MG, junho de 2008); e E: biofilmes formados na superfície interior de uma parede de taipa de pilão de edificação vernácula (Areias, SP, novembro de 2012). Fonte: acervo pessoal dos autores. 
30. Ver Cristina Chiavari et al. (2008) e Carl-Johan Bergsten et al. (2010).

31. Ver Melanie Rimmer et al. (2013).

32. Ver Leslie Morton e Susanne Surman (1994).

33. Costuma-se chamar de transformação biológica uma alteração física ou química provocada, nos materiais, por organismos vivos, geralmente bactérias, fungos, liquens ou algas. Não se trata de uma categoria diferente das outras duas. Contudo, a distinção colocada de tal forma é comum na literatura.
Digno de menção também é o estudo sobre os microambientes presentes nas diferentes partes de órgãos de tubos barrocos..$^{30}$ Uma série cuidadosa de medidas realizadas em instrumentos da Europa de 2004 a 2006 permitiu verificar graus variáveis de corrosão nos tubos de chumbo e ligas de chumbo com estanho, em parte em função da composição dos metais, mas também devido à presença de ácidos orgânicos voláteis, cuja concentração varia de um instrumento para outro. Os autores mostraram, em especial, que a frequência de uso das notas musicais pode ser um dos aspectos que controlam a incidência da corrosão, já que uma maior ou menor ventilação dos tubos influencia a dispersão dos polventes gerados in situ.

Casos literalmente microscópicos de microambientes podem ser exemplificados pelas interfaces que se estabelecem em determinadas condições entre a atmosfera e as superfícies dos materiais e que promovem (ou, vice-versa, inibem) processos de degradação de materiais. Por exemplo, é muito bem estabelecido que uma fina camada de água na superfície dos metais é indispensável para os processos de corrosão eletroquímica. ${ }^{31} \mathrm{Na}$ mesma escala, podem ser mencionados os biofilmes associados com o desenvolvimento de colônias de microrganismos, isło é, depósitos biológicos de espessura nanométrica. Os biofilmes têm papel extremamente importante na biodeteriorização de bens culturais, quer por potencializarem a ação deletéria das distintas espécies de organismos, quer por dificultarem as ações de remediação, devido às características protetoras desse filme. ${ }^{32}$

\section{FATORES DE CARACTERIZAÇÃO DOS MICROAMBIENTES PARA CONSERVAÇÃO DE BENS CULTURAIS}

De um modo geral, pode-se dizer que os principais fatores característicos de um microambiente que influenciam na estabilidade dos materiais são a temperatura, a composição química do ar (incluindo o vapor de água - e, portanto, a umidade - e os vários polventes gasosos), a presença de agentes biológicos e a incidência de ondas eletromagnéticas (por exemplo, a luz). Cada um deles determina a ocorrência de transformações físicas, químicas ou biológicas ${ }^{33}$ nos materiais, mas também a intensidade e a rapidez com que tais mudanças ocorrem, podendo tais efeitos serem mais ou menos acentuados, em função tanto dos níveis médios de cada uma dessas grandezas ao longo do tempo quanto da amplitude e da frequência de suas flutuações ou, ainda, em função das características do fenômeno (por exemplo, a incidência de um tipo específico de polvente ou de ondas luminosas de determinada energia).

Na perspectiva da Ciência da Conservação, a conservação preventiva tem como fundamento a possibilidade de antever o tipo, a magnitude e a velocidade 
dos processos de decaimento em função dos conhecimentos científicos sobre a ação dos fatores ambientais nos diversos materiais. Entretanto, ainda que existam correlações teóricas de causa e efeito muito claras entre certas propriedades do meio e determinadas transformações nos materiais, a previsão do tipo e da extensão das mudanças que podem ocorrer na prática - e, destarte, o planejamento de ações de contenção - está sujeita a toda uma série de complexidades. Estas incluem tanto as sinergias dos diversos fatores ambientais como incógnitas relacionadas à dinamicidade da composição do meio e à resposta de materiais compósitos que normalmente compõem os artefatos a serem protegidos. ${ }^{34}$ Inclui-se também o papel do histórico físico-químico prévio (envelhecimento), durante o qual transformações já aconteceram em várias direções, não sempre de forma rastreável.

Por outro lado, esse quadro é aliviado - e a questão da conservação preventiva baseada no controle ambiental ganha força - em virtude da disponibilidade de recursos tecnológicos cada vez mais precisos, acessíveis, portáteis, de reduzidas exigências energéticas, com potencialidades de comunicação a distância e pouco invasivos. A tecnologia também ajuda no que tange ao oferecimento de soluções para o controle ambiental ou ainda para promover formas de proteção adicional aos materiais contra o ataque proporcionado pelos fatores ambientais. Além disso, também não se pode negar que, mesmo em face das dificuldades e complexidades enumeradas acima, é possível propor uma abordagem, de certa forma simplificada, que foque alguns preceitos de boas práticas de manejo dos microambientes, suficientes para garantir um grau razoável de estabilidade das coleções e compatíveis com a efetiva disponibilidade de recursos tecnológicos, humanos e financeiros das instituições envolvidas na conservação dos bens culturais.

$\bigcirc$ que merece ser salientado é uma série de cautelas que, ainda que essenciais para o sucesso da conservação preventiva e, em certa medida, evidentes para os profissionais acostumados com os procedimentos da pesquisa experimental, recebem escassa atenção. São elas a conveniência e a importância de se evitar a confiança cega em normas preestabelecidas, não raramente definidas em contextos diferentes daquele que interessa ao responsável por um dado espaço de conservação e não necessariamente de validade universal; ${ }^{35}$ a compreensão dos princípios de funcionamento dos instrumentos de medição e controle e, portanto, suas exigências e limitações; o rigor na coleta e no tratamento dos dados; e a preferência pela implementação de alterações graduais e reversíveis nos microambientes em concomitância com a introdução de formas de constante reavaliação de processos e procedimentos e com a consciência da mutabilidade (por vezes imprevisível) das características dos microambientes.
34. Ver Oscar van der Brink, Gert Eijkel e Jaap Boon (2000).

35. Por exemplo, os bem conhecidos parâmetros de climatização, algumas vezes questionados em seio à comunidade dos cientistas da conservação ou julgados inadequados para determinadas situações climáticas, a dizer, regiões tropicais, como é o caso de boa parte do Brasil. 
36. A umidade relativa é a grandeza que, de fato, controla a resposta dos objetos em termos de absorção ou liberação de água e, por esse motivo, o foco dos diagnósticos ambientais para fins de conservação e muitas outras finalidades - é essa propriedade mais do que a umidade absoluta, que representa efetivamente a concentração de água na atmosfera num determinado ponto do tempo e do espaço.

37. Ver Dario Camuffo (1998).

38. Ver Garry Thomson (1986), May Cassar (1994), Dario Camuffo (1998) e Jonathan Ashley-Smith (1999).

39. Ver May Cassar (1994).

40. Por exemplo, passagens de fase (materiais como ceras que derretem a temperaturas comparativamente baixas e sólidos que sofrem alterações alotrópicas - como o já citado caso do Sn, conforme lembrado por Ashley-Smith, 1999).

41. Por exemplo, Michalski (1991) cita que materiais poliméricos encolhem tipicamente entre $0,007 \%$ e $0,014 \%$ por diminuição de $1^{\circ} \mathrm{C}$; Ashley-Smith (1999) afirma que raramente a variação dimensional supera 0,02\%/ ${ }^{\circ} \mathrm{C}$; Thomson (1986) chega a uma estimativa de $0,004 \% /{ }^{\circ} \mathrm{C}$ para as madeiras. Por outro lado, variações em UR podem resultar em mudanças dimensionais da ordem de $0,4 \%$ a $0,9 \%$ por 10 unidades de UR (na faixa de $50 \%$ a $60 \%$ de UR) no caso da madeira, $0,3 \%$ no caso do papel e de $0,1 \%$ para telas de algodão. Esses valores estão citados somente para dar uma ideia da ordem de grandeza dos efeitos causados pelas variações dos parâmetros microclimáticos. Entretanto,

\section{Temperatura e umidade relativa}

Uma revisão sintética da ação dos fatores ambientais nos materiais pode começar por temperatura (T) e umidade relativa (UR). ${ }^{36}$ Há consenso em abordar essas duas variáveis conjuntamente, seja porque um eventual descontrole de uma ou da outra tende a gerar problemas da mesma natureza nos materiais, como será visto abaixo, seja porque elas estão fisicamente interligadas entre si. Lembramos, com Camuffo, ${ }^{37}$ que a UR é definida como a razão entre a massa de vapor de água efetivamente presente em um determinado volume de ar $\left(m_{v}\right)$ e a máxima quantidade em massa de vapor de água no mesmo volume de ar àquela temperatura $\left(m_{v, s a}\right)$, a partir da qual a água, portanto, sofre condensação e considerada a quantidade de saturação:

$$
\operatorname{UR}(\%)=\frac{m_{v}}{m_{v, \text { sat }}} \times 100
$$

Além disso, a paridade de concentração absoluta (em massa) de água na fase de vapor, uma variação da T gera uma resposta inversamente proporcional na UR. Isso significa que, num curto prazo e admitindo variações mínimas da quantidade absoluta de água, o aumento da $T$ de um microambiente tem como resultado a diminuição da UR e vice-versa.

A temperatura e a umidade relativa do ar, num determinado microambiente, influenciam a temperatura e o conteúdo de água dos objetos e essas duas propriedades afetam todos os tipos de processos de deterioração dos materiais mencionados antes, isto é, desgaste mecânico, degradação química e biodeterioração. ${ }^{38}$

O desgaste mecânico é um processo associado a flutuações mais ou menos abruptas na T e na UR, a não ser quando for consequência de processos de decaimento químico (por exemplo, a despolimerização da celulose em substratos de papell. Contudo, nessa dinâmica, o efeito da UR é considerado geralmente mais marcante: Cassar chega a sugerir que os objetos apresentam, com a umidade relativa, a mesma sensibilidade que as pessoas têm com relação à temperatura do meio e suas variações. ${ }^{39}$ Efetivamente, com exceção de situações isoladas, ${ }^{40}$ no intervalo de temperaturas que se espera normalmente em microambientes minimamente controlados, a variação de temperatura leva a alterações mecânicas relativamente modestas. ${ }^{41}$

Em suma, olhando do ponto de vista da estabilidade mecânica dos materiais e com foco naqueles de tipo higroscópico, a tendência é sempre procurar cuidar de ambientes que apresentem as menores amplitudes possíveis de flutuações de 
UR. Contudo, a questão é como definir intervalos seguros de oscilação, e isso tem sido tema de várias considerações por vários autores.

Ashley-Smith ${ }^{42}$ apresenta uma solução fechada para os materiais considerados mais sensiveis e fixa em $\pm 5 \%$ o limite para garantir ausência de danos mecânicos ou $\pm 10 \%$ para danos mínimos.

Michalski ${ }^{43}$ utiliza os mesmos valores de amplitude de UR, mas frisa de maneira mais acentuada a diferença entre variações de umidade de curto prazo (diárias) e sazonais e, em função disso, nas recomendações da ASHRAE, propõe uma classificação de ambientes em cinco tipologias de microambientes distintas em nível de risco para as coleções e, portanto, diferentemente apropriada para diversos tipos de acervos.

Camuffo ${ }^{44}$ também frisa a importância de variações sazonais, tipicamente mais expressivas do que as diárias, mas destaca igualmente a necessidade de evitar ou minimizar situações de fadiga associadas com ciclos frequentes de flutuações de UR que acentuam a vulnerabilidade dos artefatos higroscópicos. Por outro lado, o mesmo autor discute, em diversos momentos, o papel da trajetória pregressa dos objetos e sustenta a tese da manutenção de condições microclimáticas comparáveis com os registros históricos daquele mesmo espaço, tanto em termos de níveis médios como de faixas permitidas de oscilação. ${ }^{45}$

A dependência da degradação química da temperatura se dá, no intervalo de valores esperado para microambientes convencionais, sobretudo pela dependência de tipo exponencial da velocidade de reações químicas dessa grandeza, de acordo com os princípios da cinética química.

No caso da umidade relativa do ar, esse é o principal parâmetro que controla o conteúdo de água por parte dos materiais. Thomson ${ }^{46}$ e Camuffo ${ }^{47}$ indicam que os materiais mais sujeitos à influência do conteúdo de água, isto é, da UR do ar, são: os monumentos e as edificações em pedras calcárias /p. ex.: mármore), por causa da ação de polventes ácidos; materiais porosos de alvenaria, devido ao transporte e à precipitação de sais solúveis (eflorescência); metais, em decorrência dos processos de corrosão; alguns tipos de vidro; madeira, papel, couro, pergaminho e fibras em geral, por conta da hidrólise das cadeias de celulose e proteínas.

No que diz respeito à questão da ação química de temperatura e umidade, alguns autores buscam modelar numericamente os efeitos de determinados cenários de condições microclimáticas visando quantificar a extensão de danos futuros e manejar o risco. Assim, Sebara ${ }^{48}$ e Michalski49 trabalham com o conceito de linhas de isopermanência (isoperms), ou seja, diagramas de UR vs. T em que cada linha num exercício simbólico baseado nos dados de Thomson (1986), podemos estimar grosseiramente que, no caso de madeiras acondicionadas num ambiente a $25^{\circ} \mathrm{C}$ e $50 \%$ de UR, uma diminuição de temperatura de $5^{\circ} \mathrm{C}$ induziria um encolhimento térmico de $-0,02 \%$ que, porém, seria amplamente sobrepujado por uma expansão associada à absorção de água de no mínimo $+0,72 \%$, considerando um aumento simultâneo da UR para aproximadamente $68 \%$. Por outro lado, há de se considerar que a variação dimensional dos materiais em face da UR é mais dramática nas extremidades da escala de UR, ou seja, em faixas de UR muito elevadas ou muito baixas, os efeitos das flutuações de UR são significativamente mais prejudiciais.

42. Ver Jonathan Ashley-Smith (1999).

43. Ver ASHRAE (2011).

44. Ver Dario Camuffo (1998).

45. Ver Lukasz Bratasz, Dario Camuffo e Roman Kozlowski (2007) e Alessia Caratelli et al. (2013).

46. Ver Garry Thomson (1986).

47. Ver Dario Camuffo (1998).

48. Ver Donald Sebera (1988).

49. Ver Stefan Michalski (2002). 
50. Ver Dennis Allsopp, Kenneth Seal, Christine Gaylarde (2004)

51. Ver Garry Thomson (1986).

52. Ver Hannu Viitanen et al. (2010). corresponde a situações de tempo de vida constante para um determinado tipo de material. Os gráficos, construídos com base nas equações que governam a dependência da velocidade de reação (de hidrólise) da T (equação de Arrhenius) e da quantidade de água, conforme descrito por Sebara, permitem definir ganhos e perdas em tempo de vida útil de um material quando da alteração de UR e/ou T. Ou, ainda, possibilitam calcular a compensação em UR (ou T) resultante de uma variação em T (ou UR) necessária para garantir tempo de vida útil constante.

\section{Agentes biológicos}

A ação de organismos vivos - ou, mais especificamente, microrganismos como fungos, bactérias, liquens e algas - que provoca alterações indesejadas na estrutura e nas propriedades dos objetos se denomina biodeterioração. ${ }^{50} \mathrm{~A}$ biodeterioração pode decorrer simplesmente da colonização de um substrato (por exemplo, a criação de ninhos de insetos numa parede) ou, mais radicalmente, envolver a degradação das moléculas do material para a obtenção de energia vital por parte dos microrganismos (como é o caso da digestão de celulose presente em materiais de origem vegetall. Em outros casos, o dano surge como um efeito secundário a esses dois processos principais no desenvolvimento dos agentes biológicos, por exemplo, quando ocorre emissão de dejetos metabólicos, eventualmente coloridos: nesse caso, predomina (ou se soma) o efeito estético ao decaimento mecânico. $\bigcirc$ impacto nos bens culturais é bastante evidente e foi objeto de inúmeros estudos ao longo dos anos. As infestações não se restringem a compostos orgânicos, mas comprometem também substratos inorgânicos como concreto, pedras, vidros e metais.

A biodeterioração, por depender da ação de organismos vivos e, portanto, de caminhos metabólicos mediados por enzimas, é dramaticamente influenciada pela temperatura e pelo conteúdo de umidade dos substratos onde acontece. Geralmente, considera-se que, para o crescimento de microrganismos, são necessárias condições de umidade bastante severas, sendo que o nível de segurança aceito pela maioria dos autores, a partir do qual a probabilidade de biodeterioração se torna muito elevada - sobretudo por fungos e insetos -, é de $70 \%$ de umidade relativa do ambiente. Thomson ${ }^{51}$ salienta, por exemplo, que a manutenção de valores baixos de UR pode efetivamente ser uma medida efetiva no bloqueio da biodeterioração, mas não necessariamente erradica a infestação por microrganismos e seus esporos. Nesse quadro, Viitanen ${ }^{52}$ observa que, ao se considerar as taxas de crescimento dos microrganismos, é necessário levar em conta outros fatores, 
sobretudo o nível de nutrientes presentes e o pH da superfície. Temperaturas na faixa de $20^{\circ} \mathrm{C}$ a $35^{\circ} \mathrm{C}$ são tidas como geralmente favoráveis ao desenvolvimento de todos os microrganismos, muito embora existam diferenças expressivas entre espécies agressoras.

A degradação dos materiais provocada pelos insetos constitui um amplo capítulo à parte, sobretudo em climas tropicais. Em síntese, no que diz respeito ao efeito de temperatura e umidade relativa, foi observado que efetivamente os insetos presentes em locais de conservação, como museus, bibliotecas, arquivos e igrejas, de fato se instalam em microambientes bastante confinados, os quais apresentam características específicas, em muitos casos mais quentes e mais úmidos que o ambiente circunstante. ${ }^{53}$ Esses fatores são determinantes para o desenvolvimento desses organismos, juntamente com outros, notadamente a disponibilidade de alimento. Temperaturas entre $25^{\circ} \mathrm{C}$ e $35^{\circ} \mathrm{C}$ e umidades acima de $75 \%$ são ideais, mas não indispensáveis. As temperaturas elevadas proporcionam um maior nível de mobilidade, uma maior taxa de deposição dos ovos e tempos de incubação mais curtos. Com relação à umidade do ambiente e dos materiais, essa é fundamental porque constitui a fonte da água de que precisam. Apesar de protegidos contra a eliminação de água por transpiração, temperaturas muito elevadas ou ambientes muito secos podem levar à morte dos insetos por ressecamento. As temperaturas baixas limitam o metabolismo e o cruzamento entre os insetos, sendo que, em condições abaixo do zero, é possível promover sua efetiva eliminação, desde que num prazo de tempo adequadamente estendido. $\bigcirc$ confinamento de objetos infestados em condições anóxicas ou em baixas temperaturas é um método utilizado para a erradicação desse tipo de praga.

Uma questão bastante debatida nos últimos anos é o cenário de ampliação da contaminação por insetos em ambientes indoor como resultado das alterações climáticas já previstas para o século XXI e em sinergia com a redução do uso de pesticidas de amplo espectro de ação, empregados no passado e hoje já amplamente banidos. Esforços já estão sendo focados em estender os modelos de previsão climática para os ambientes indoor e para compreender como isso será refletido pela maior (ou menor) presença de pragas biológicas. Brimblecombe e Lankester ${ }^{54}$ trabalham com as perspectivas de alteração na alternância de dias frios $\left(<10^{\circ} \mathrm{C}\right)$ e dias quentes e apresentam resultados em termos de projeções quanto ao crescimento de um besouro usado como modelo no estudo. É claro que essa investigação abre uma série de questões a serem entendidas com maior precisão, de maneira a criar as condições para adequadas estratégias de adaptação e mitigação. 
55. Ver Garry Thomson (1986).

56. Ver Robert Feller (1994) e Terry Schaeffer (2001).

57. Ver René de la Rie (1989).

58. Ver Karen Trentelman e Leon Stodulski (1996).

\section{Radiação luminosa}

Certamente, pode-se dizer que o tipo de radiação luminosa, a intensidade e seus ciclos são fatores que diferenciam de forma dramática os microambientes internos do ambiente externo, seja porque as áreas interiores das edificações são muitas vezes dotadas de sistemas artificiais de iluminação lou isoladas da incidência de luz natural de forma artificial), seja porque, mesmo quando recebem luz solar, esta alcança as superfícies e os objetos de forma modificada. É claro que, em termos de incidência de luz, dentro do museu existem diversos microambientes, justamente distintos em tipo e quantidade de luz. Thomson ${ }^{55}$ observa como é possível evidenciar a ação da luz pela comparação de superfícies expostas diretamente à radiação com aquelas que ficam protegidas de uma maneira ou de outra: a moldura de um quadro, o revés de um tapete ou de uma tapeçaria.

Ao se tratar dos efeitos deletérios da radiação luminosa nos materiais (fotodegradação), entende-se, em princípio, que sua ação decorre da absorção de energia luminosa da região do visível ou ultravioleta por parte dos sistemas moleculares, desconsiderando-se nessa categoria os processos de degradação disparados pela incidência de radiação infravermelha, que provoca efeitos meramente térmicos. Também, considera-se sobretudo a ação direta da luz sobre os materiais dos artefatos, muito embora possa haver consequências indiretas - por exemplo, na composição química do ar.

No que diz respeito à ação direta da radiação visível ou ultravioleta (UV) em processos de degradação dos materiais, esse efeito é muito mais marcante em compostos orgânicos, ${ }^{56}$ sobretudo corantes, porque, nesse caso, a absorção de luz é implícita nas propriedades cromáticas da molécula e o resultado final é claramente relevante e fácil de detectar e quantificar. Ademais, é sabido que determinados substratos, como lã e seda, conferem sensibilidade adicional aos corantes. Entretanto, há várias pesquisas que investigaram também materiais incolores, como vernizes, ${ }^{57}$ componentes de óleos secantes (sobretudo de linhaça), outras matrizes usadas como aglutinantes em tintas (gema de ovo, muito comum em pinturas a têmpera) e também fibras à base de celulose ou proteínas, como lã e seda, ou ainda sistemas poliméricos sintéticos. No âmbito dos compostos inorgânicos, pode-se citar a transformação de vários pigmentos provocada pela incidência de luz, como a mudança de realgar (laranja-vermelho) para pararrealgar (amarelo) $)^{58}$ e as alterações no vermelhão, no azul-da-prússia e em compostos à base de cobre, como a malaquita e os acetatos básicos de cobre. A transformação fotoquímica de pigmentos à base de cromato de chumbo teve um destaque particular em função do uso desse tipo de pigmento por Vincent 
van Gogh (1853-1890) e nos problemas de fotodegradação sofridos por suas pinturas ao longo dos anos. ${ }^{59}$

Ora, se, para a estabilidade de uma importante gama de materiais, a incidência de radiação luminosa e de UV representa realmente um sério risco, é também verdade que a incidência de luz é um parâmetro ambiental de manejo relativamente fácil do ponto de vista da gestão dos microambientes, ainda que a irradiação de objetos por luz visível seja uma necessidade intrínseca do uso social e científico de bens culturais.

A gestão da iluminação se baseia em três tipos de abordagens: controle do tipo de radiação, controle da intensidade da radiação e controle da duração da exposição do objeto à radiação. As primeiras duas estratégias focam a escolha da fonte de iluminação, no uso de barreiras e filtros entre a origem da radiação e os objetos ou ainda em esquemas que permitem ajustar o ângulo de incidência do feixe de luz sobre as superfícies. ${ }^{60}$ Já a terceira depende eminentemente de protocolos de funcionamento das instituições.

Não cabe aqui entrar no mérito específico das opções de lâmpadas existentes no mercado e que, de qualquer forma, estão sujeitas a contínuas inovações tecnológicas. O que parece importante observar são alguns elementoschave na avaliação da iluminação de um microambiente e no processo de tomada de decisão voltado para a conservação dos bens materiais:

i) O tipo de lâmpada escolhido (ou o uso de luz solar) influencia primeiramente $\circ$ espectro de emissão e, portanto, o conjunto de ondas eletromagnéticas que compõem o feixe luminoso e sua frequência/comprimento de onda, sendo importante lembrar a dependência inversa entre a energia "transportada" e o comprimento de onda, fazendo com que, quanto mais curta for a onda, maior o seu impacto potencial. Nessa perspectiva, há consenso geral de que é preciso esforço específico para impedir a incidência de radiação UV, presente na luz solar e em várias lâmpadas, como as de xenônio e, em certa medida, de fluorescência. Por outro lado, a presença de radiação infravermelha pode induzir efeitos térmicos nas superfícies de incidência, em decorrência da excitação de estados vibracionais e rotacionais, fato que não deveria ser negligenciado e que sugere cuidados com fontes incandescentes e, novamente, lâmpadas de xenônio.

ii) A intensidade da fonte influencia a ação da radiação luminosa sobre os materiais porque se considera que, dado um determinado rendimento quântico, o efeito fotoquímico líquido é proporcional à quantidade total de fótons projetados ao longo do tempo na superfície do material. Como essa quantidade, por sua vez, está diretamente associada à quantidade de fótons emitida por unidade de tempo
59. Ver Letizia Monico et al. (2011).

60. Ver Garry Thomson (1986). 
61. Ver Garry Thomson (1986), Robert Feller (1994) e Terry Schaeffer (2001).

62. Ver James Druzik e Bent Eshøj (2007).

63. Grandeza que relaciona o fluxo luminoso com a superfície de incidência. $\mathrm{Na}$ prática, é a quantidade de luz num determinado ambiente e se mede em lux $=$ lumen $\mathrm{m}^{-2}$.

64. Ver Garry Thomson (1986).

65. Ver Robert Feller (1964).

66. Ver Robert Feller (1964), Garry Thomson (1986), Stefan Michalski (2001) e James Druzik e Bent Eshøj (2007).

67. Ver Stefan Michalski (2001).

68. Ver Stefan Michalski (2001.

69. Ver Garry Thomson (1986).

70. Ver Terry Schaeffer (2001). pela fonte (intensidade), o efeito fotoquímico líquido estará diretamente relacionado ao produto da intensidade da fonte pelo tempo, o que se denomina de lei de reciprocidade. ${ }^{61}$ Isso equivale a afirmar que o efeito da luz é cumulativo e que, portanto, pode-se obter o mesmo efeito reduzindo tanto o tempo de exposição como a intensidade da iluminação na mesma proporção, pois a quantidade acumulada de efeito (ou dano) nos dois casos será igualmente reduzida. Essa visão é claramente simplificada e não se aplica de forma rigorosa, mas fornece uma regra grosseira para avaliar o resultado de uma determinada decisão em termos de intensidade ou de tempo de exposição. Por exemplo, a exposição de uma superfície a um fluxo de radiação de 1000 lux por uma hora resultará no mesmo dano que um fluxo de 10 lux por cem horas, pois em ambos os casos haverá o fornecimento de uma dose de 1.000 lux $\cdot h$.

De um modo geral, entre os conservadores, tem-se estabelecido a prática de garantir a quantidade de luz mínima que proporcione um nível adequado de "performance visual"62 compatível com a classe de estabilidade dos materiais, isto é, uma iluminância ${ }^{63}$ de 200 lux $x^{64}$ ou 120-150 lux $x^{65}$ para materiais mais estáveis ou 50 lux de uma maneira mais generalizada ou pelo menos para materiais mais fotossensíveis. ${ }^{60}$ Essa seleção já comporta uma solução para aquilo que Michalski ib7 define como "o dilema fundamental da iluminação: visibilidade versus vulnerabilidade", ou seja, a necessidade de conciliar um conforto visual mínimo e a devida valorização de cores, contraste e destaque de detalhes, de um lado, com a garantia de um determinado grau de proteção para os materiais, do outro. Entretanto, as especificações baseadas tanto na apreciação visual como nas metas de conservação podem ser ajustadas: o mesmo autor ${ }^{68}$ propõe a possibilidade de uma intensificação do nível de intensidade/iluminância de um fator 3 em casos específicos (necessidades relacionadas a objetos escuros, desenhos/pinturas de baixo contraste, observadores idosos e/ ou necessidade de pesquisas detalhadas), a ser compensada por adequados intervalos de falta de iluminação, justamente em função da lei da reciprocidade. Nesse aspecto, podem ser mencionadas estratégias baseadas em: i) redução do tempo de exposição ao público; ii) aplicação de um rodízio de exposição dos objetos; iii) garantia de ausência de luz em dias/horário de fechamento do espaço ao público; iv) imposição de iluminação somente na presença de pessoa do público na frente do artefato.

Nesse quadro, um tema bastante debatido é a conveniência do uso de câmeras fotográficas com flash. Thomson ${ }^{69}$ cita trabalhos que sugerem que, usadas com moderação, lâmpadas flash não apresentam efeitos significativos, apesar de serem baseadas em fontes ao xenônio la estimativa dos autores leva em consideração a efetiva quantidade de fótons projetada numa superfície por flash de duração típica de 10 ms e em determinados cenários de visitação). Schaeffer, 70 
já num outro contexto tecnológico, tende a confirmar as posições de Thomson em linha de princípio, estimando que cada tomada resultaria numa iluminância de 700 lux por um tempo, como foi dito, drasticamente reduzido. O tema continua ainda relativamente debatido, com posições mais ou menos conservadoras. Entretanto, salienta-se que o panorama desses últimos anos sofreu mudanças bastante significativas com a difusão em massa de câmeras digitais integradas a aparelhos telefônicos portáteis. Na onda dos avanços crescentes na direção de dimensões cada vez mais reduzidas, a introdução de LEDs de luz branca parece apontar para um progresso com relação aos flashes ao xenônio. Significativo é o corte de radiação no UV-A, muito embora a permanência de uma porção significativa de ondas na região do azul deva encorajar uma atitude cautelosa.

\section{Composição química da atmosfera}

Vários autores, ao tratar da questão do efeito de alterações na composição atmostérica ao redor dos objetos do patrimônio cultural material, remetem para os relatos de Michael Faraday (1791-1867) sobre os efeitos da poluição nas pinturas da National Gallery de Londres, por volta da década de 1850. ${ }^{71}$ Certamente não é um mero acaso que esse tipo de preocupação tenha começado a se impor justamente na cidade onde coincidiram, ao longo do século XIX, o forte desenvolvimento industrial e o estabelecimento de instituições de monumental importância no panorama da museologia, como o British Museum (1759), a National Gallery (1838) e o Museu de História Natural (1880). Por muitas décadas, Londres foi uma das cidades com os maiores níveis de polvição ${ }^{72}$ e hoje, com o controle do tradicional problema de smog ácido, a preocupação tem se deslocado para grandes megalópoles afetadas por smog fotoquímico, ligado principalmente às emissões veiculares e à incidência de radiação solar. Cidades como Los Angeles, Cairo, Cidade do México e São Paulo estão entre as mais atingidas pelo problema. Em particular, a região metropolitana de São Paulo hoje reúne uma série de condições particularmente propícias para uma situação de forte preocupação com a polvição atmosférica: ${ }^{73}$ uma população de quase 20 milhões de habitantes, uma frota veicular de 6,5 milhões, temperaturas médias mensais entre $15^{\circ} \mathrm{C}$ e $24^{\circ} \mathrm{C}$ com um nível de incidência total de energia solar, em média, proporcionalmente superior aos de Nova lorque (16\%), Paris (48\%) e Berlim (70\%).

Vê-se, então, como a história mostra uma constante (e evidente) associação entre os locais mais atingidos por problemas de polvição atmosférica e os centros onde mais se concentram instituições de abrigo e proteção de bens culturais, muito
71. Ver Norbert Sebastian Baer e Paul Banks (1985).

72. Por muitos anos, a cidade de Londres sofreu por um dos mais altos níveis de poluição do planeta, em decorrência das elevadas emissões de substâncias químicas e das próprias condições climáticas da região, que alcançaram o ápice cerca de cem anos depois dos alertas de Faraday, com o tristemente famoso episódio do Great Smog de dezembro de 1952. A aplicação, nas décadas seguintes, de políticas de controle da qualidade do ar (Clean Air Acts, 1956 e 1968) teve um papel excepcional na redução do problema da poluição urbana.

73. Ver Andréa Cavicchioli, Ravi Orsini Camargo de Souza e Guilherme Ranieri Reis (2013). 
74. Ver Dalva Lúcia Araújo de Faria e Thiago Sevilhano Puglieri (2013).

75. Ver Annika Niklasson et al. (2008).

76. Ver Peter Brimblecombe (1990).

77. Ver Cynthia Shaver, Glenn Cass e James Druzik (1983), Paul Whitmore e James Druzik (1987), Paul Whitmore e Glenn Cass (1988), Glenn Cass et al. (1989), Glenn Cass et al. (1991) e William Nazaroff (1993). embora seja incorreto estabelecer uma relação necessária e suficiente entre poluição atmosférica urbana e os impactos no patrimônio cultural material. Primeiramente, porque a poluição das grandes cidades constitui um problema com características muito variáveis entre uma localidade e outra, em função de inúmeros fatores climáticos, sociais, políticos e econômicos: o tamanho da cidade e sua população podem não estar diretamente correlacionados ao risco na estabilidade dos materiais associado à polvição, ainda que o meio urbano sempre implique determinado grau de alerta. Em segundo lugar, porque, numa série muito extensa de situações, o impacto atmosférico é decorrente de concentrações não ligadas a emissões antropogênicas ou, pelo menos, a atividades intensas como aquelas que ocorrem nos centros urbanos. Alguns dos exemplos citados na literatura são representativos dessa questão: a degradação de esculturas policromadas em chumbo do Museu do Oratório de Ouro Preto $^{74}$ e a agressão química nos tubos de órgãos barrocos em pequenas cidades do norte da Alemanha ou em vilarejos dos Alpes italianos. ${ }^{75}$

No âmbito da ciência da conservação, o momentum das pesquisas focadas na ação dos polventes atmosféricos em microambientes indoor acontece nas décadas de 1980 e 1990. Os artigos de Peter Brimblecombe ${ }^{76}$ e de um conjunto de pesquisadores incentivados pelo Getty Conservation Institute ${ }^{77}$ representam marcos científicos bastante importantes, e a relação de polventes e de seus efeitos apresentada naqueles trabalhos ainda serve como base para uma abordagem descritiva. Com apoio nessa literatura, um ponto de partida conveniente consiste em distinguir polventes de origem predominantemente externa e polventes tipicamente associados a fontes internas às edificações.

Na primeira categoria podem ser considerados o dióxido de enxofre $\left(\mathrm{SO}_{2}\right)$, os óxidos de nitrogênio $\left(\mathrm{NO}, \mathrm{NO}_{2}\right)$, ozônio e outros componentes oxidantes do smog fotoquímico e o material particulado inalável $\left(M P_{10}+M P_{2,5}\right)$.

Como amplamente sabido, o $\mathrm{SO}_{2}$ é um dos principais compostos de enxofre na atmosfera, sendo formado durante processos de combustão de materiais orgânicos que contêm enxofre em sua composição. $\mathrm{O}$ principal impacto do $\mathrm{SO}_{2}$ é a lixiviação das superfícies decorrente da redução do pH das águas de chuva (chuvas ácidas), particularmente intensa nos materiais de construção de edificações e monumentos ricos em carbonatos, como o mármore. Além disso, o $\mathrm{SO}_{2}$ pode migrar para ambientes indoor e lá interagir com as superfícies sólidas a uma velocidade (velocidade de deposição) dependente das propriedades do material. Superfícies alcalinas como alvenaria e argamassas expostas apresentam os valores mais altos, ao passo que metais, madeiras, papéis e têxteis são caracterizados por velocidades de deposição intermediárias. $\bigcirc$ valor depende muito da umidade do 
ambiente e do estado de conservação do material. Outros materiais também sujeitos a agressão por parte do $\mathrm{SO}_{2}$ são aqueles à base de polímeros hidrolisáveis, como celulose e proteínas (e, portanto, papel, couro, pergaminho e fibras têxteis). Graedel e McGill78 apresentam uma tabela muito simplificada, em que são ranqueados os efeitos de vários polventes em algumas categorias de materiais e que, de um modo geral, reflete as considerações que foram repetidas ao longo dos anos por outros pesquisadores. ${ }^{79} \bigcirc$ efeito do $\mathrm{SO}_{2}$ em corantes e pigmentos é considerado menos impactante, ainda que não desprezível, e, de qualquer forma, sempre dependente da natureza química do composto e de outras condições, como o tipo de substrato, a umidade, a presença de outras espécies no meio.

As concentrações de $\mathrm{SO}_{2}$ têm sistematicamente diminuído ao longo dos últimos anos, numa tendência que se refletiu também no Brasil e na região metropolitana de São Paulo. Nesse quadro, hoje o foco da atenção deslocou-se para os polventes ligados ao fenômeno do smog fotoquímico, em que óxidos de nitrogênio, ozônio, radicais livres e compostos orgânicos assumem um papel de destaque. No tocante ao grupo dos óxidos de nitrogênio $\left(\mathrm{NO}_{x}\right)$, sua formação e acúmulo se dão principalmente a partir de processos de combustão. A ação ácida dos $\mathrm{NO}_{x}$ decorrente de sua transformação em ácido nítrico $\left(\mathrm{HNO}_{3}\right)$ é considerada, em geral, parecida com a de $\mathrm{SO}_{2}$. Contudo, as velocidades de deposição nos mesmos materiais vistos para $\mathrm{SO}_{2}$ são menores.

Em relação bastante direta com a preocupação pelas concentrações de $\mathrm{NO}_{x}$, o ozônio $\left(\mathrm{O}_{3}\right)$ e os demais componentes do smog fotoquímico compõem um outro conjunto de polventes de origem predominantemente externa com importantes efeitos nos materiais e nos bens culturais. $\bigcirc$ ozônio é um polvente secundário e resulta da formação prévia de $\mathrm{NO}_{x}$ e sua posterior transformação na presença de luz. As concentrações de $\bigcirc_{3}$ na baixa troposfera lozônio troposférico, para diferenciar do mesmo gás presente na camada de ozônio, na estratosfera) têm certamente aumentado em muitos centros urbanos desde os anos de 1970 até hoje e São Paulo seguiu essa tendência. Numa escala global, o IPCC 80 indica, com cautela, a probabilidade de aumentos da ordem de 1-5 ppb/década no hemisfério Norte e 2 ppb/década no hemisfério Sul de 1970 até hoje, apesar de registrar indicações muito prováveis de que, entre o século XIX e o final do século XX, a Europa tenha dobrado o nível médio desse composto na troposfera. Os efeitos do ozônio nos materiais são revistos pelos vários autores em função de interesses específicos voltados para os bens culturais. ${ }^{81}$ A ênfase é geralmente na reatividade específica do $\bigcirc_{3}$ com relação a corantes orgânicos e na aceleração de processos de autoxidação, resultando no ataque aos materiais poliméricos naturais (celulose, proteínas, lipídeos, sistemas terpênicos, borracha) e sintéticos (materiais plásticos em geral) e coadjuvando no ataque oxidante de metais (por exemplo, Ag e Cu,
78. Ver Thomas Graedel e Ron McGill (1986).

79. Ver Norbert Sebastian Baer e Paul Banks (1985) e Cecily Grzywacz (2006).

80. Ver Dennis Hartmann et al. (2013).

81. Ver Cynthia Shaver, Glenn Cass e James Druzik (1983), Norbert Sebastian Baer e Paul Banks (1985), Garry Thomson (1986), Paul Whitmore e James Druzik (1987), Paul Whitmore e Glenn Cass (1988), Glenn Cass et al. (1989), Peter Brimblecombe (1990), Glenn Cass et al. (1991), William Nazaroff (1993), Nigel Blades et al. (2000), Jean Tétreault (2003) e Cecily Grzywacz (2006). 
82. Ver Glenn Cass et al. (1989).

83. Ver Josep Grau-Bové e Matija Strlic (2013).

84. Cf. Cecily Grzywacz (1998).

85. Ver Cecily Grzywacz (2006).

86. Ver Alexandra Schieweck et al. (2005) e Alexandra Schieweck et al. (2007). com evidentes consequências nos materiais fotográficos) e na ação ácida de $\mathrm{SO}_{2}$ e $\mathrm{NO}_{x}$. Em suma, trata-se de um poluente de ampla ação, como também observado por Cass et al. ${ }^{82}$

O material particulado constitui um último caso importante de polvente de origem tipicamente externa e do meio urbano. Atualmente, na cidade de São Paulo, as concentrações médias anuais de $M P_{2,5}$ são bastante elevadas se comparadas aos padrões de qualidade do ar dos Estados Unidos ou ao valor-guia da Organização Mundial da Saúde (OMS), chegando a até $48 \%$ do padrão anual americano e a $100 \%$ do valor-guia anual proposto pela OMS. Diversos estudos tendem a confirmar que a poluição externa é a principal fonte de partículas finas de origem antrópica para o interior do museu, ainda que sistemas de ventilação mecânica apresentem algum grau de eficiência na remoção dessas partículas, sobretudo as grossas, sendo menos adequados para a remoção de partículas finas que contribuem para o dano nos artefatos, especialmente o enegrecimento associado a black carbon (soiling, em inglês). ${ }^{83}$ Há consenso, na literatura, de que a deposição de partículas finas em superfícies é mais perigosa, pois elas tendem a ocasionar danos por transportarem compostos especificamente nocivos para os materiais.

Com relação aos polventes de origem interna, cabe mencionar que, historicamente, a ideia de investigar essa problemática em áreas destinadas à conservação de bens culturais decorreu de questões ligadas à ação de compostos orgânicos voláteis da categoria das carbonilas:

In 1987, we began investigating organic carbonyl pollutant concentrations in museum environments. This was shortly after the Hatchfield and Carpenter study on formaldehyde levels. We used active sampling to quantify the levels of aldehydes, specifically formaldehyde and acetaldehyde, low molecular weight carboxylic acids; formic acid and acetic acid. [...] The highest concentrations were detected in show cases and storage cabinets. ${ }^{84}$

Essas substâncias têm suas emissões ligadas aos materiais utilizados na decoração de ambientes interiores, acabamento e objetos empregados para as diversas funcionalidades dos espaços utilizados. Assim, madeiras e laminados, tintas e colas são tidos como os principais responsáveis pelas emissões de formaldeído, ácido fórmico e ácido acético, ${ }^{85}$ mas há também relatos de emissões ligadas aos próprios materiais e objetos conservados. A presença de certas substâncias decorre do uso de material de limpeza e de outras atividades específicas, como a desinfestação de pragas ou a preservação de espécimes animais e vegetais. ${ }^{86}$ Nesse sentido, a contaminação por conservantes (formol) e pesticidas orgânicos e inorgânicos (por exemplo, à base de cromo, chumbo e arsênio) representa um fator específico de preocupação para a saúde humana nos 
museus de zoologia e etnografia (embora não necessariamente somente esses), em especial quando são particularmente antigos e possivelmente ainda estão contaminados com substâncias persistentes amplamente usadas no passado e hoje banidas (como - DDT). Os efeitos são mais intensos em microambientes mais restritos, em que a acumulação dessas substâncias pode ser incentivada pela escassa ventilação, como gabinetes de exposição, vitrines, armários, gavetas, caixas de acondicionamento. Os materiais mais sujeitos a agressão por parte de compostos carbonílicos e carboxílicos são os metais, os substratos calcários e, de um modo geral, todos os substratos que apresentam sensibilidade ao ataque ácido - portanto, tecidos, material fotográfico, papel, couro e pergaminho. ${ }^{87}$ Também merecem uma menção especial a presença e a ação de compostos de enxofre reduzido, sobretudo sulfeto de hidrogênio $\left(\mathrm{H}_{2} \mathrm{~S}\right)$. Seu principal efeito é o ataque aos metais, sobretudo prata. Tais substâncias não são estritamente gases de origem indoor. Entretanto, é possível haver fontes bastante significativas dentro dos museus e dos demais locais de conservação, em função, principalmente, da decomposição de materiais orgânicos (lã, fibras proteicas, colas animais, plumas) e da presença de visitantes. Deve-se lembrar que polventes de origem predominantemente externa podem ter fontes internas que se sobrepõem à contribuição outdoor de maneira significativa e potencialmente perigosa para os bens culturais. $\bigcirc$ $\mathrm{O}_{3}$, por exemplo, é gerado em proximidade de descargas elétricas ou de fontes luminosas muito intensas, como nas fotocopiadoras. Stabile et al. ${ }^{88}$ destacam o uso de velas como fonte de $\mathrm{SO}_{2}$ nas igrejas; no mesmo tipo de ambiente, Spolnik et al. , 89 entre vários outros autores, notaram a influência de atividades litúrgicas, como a queima de incensos, na elevação dos níveis de material particulado e black carbon nos templos religiosos.

\section{MONITORAMENTO MICROAMBIENTAL NA CONSERVAÇÃO PREVENTIVA: O CASO DA CASA DE DONA YAYÁ, EM SÃO PAULO}

Existem poucas dúvidas quanto ao fato de a conservação preventiva somente poder ser alcançada mediante ações cuidadosamente planejadas e estratégias focadas de gestão, aquilo que em inglês é chamado de managerial component. ${ }^{90}$ No entanto, sua possibilidade de implementação começa pelo reconhecimento da centralidade da ação dos fatores ambientais já discutidos e perpassa, antes de tudo, por um detalhado diagnóstico microambiental, que eventualmente pode envolver várias escalas espaciais.

monitoramento microambiental pode parecer uma façanha meramente técnica, logo dependente unicamente da disponibilidade de recursos tecnológicos
87. Ver Cecily Grzywacz e Norman Tennent (1994), Lorraine Gibson et al. (1997) e Cecily Grzywacz (2006).

88. Ver Luca Stabile, Fernanda Fuoco e Giorgio Buonanno (2012).

89. Ver Zoya Spolnik et al. (2004).

90. Ver Jeffrey Levin (1992). 
91. Ver Maria Cecilia França Lourenço (2001). e humanos. Na verdade, essa tarefa apresenta uma série de desafios e implica um cuidadoso planejamento que influencia a qualidade dos resultados e é o pressuposto para uma correta avaliação do espaço e para a obtenção de respostas eficazes para $\mathrm{o}$ alcance dos objetivos propostos.

As questões a serem abordadas num projeto de monitoramento incluem a escolha do que monitorar, onde, com que frequência, quais as ferramentas a serem usadas e como identificar as variáveis que podem influenciar as medições e os procedimentos para realizar o processo sem provocar interferências no funcionamento da instituição nem as sofrer a partir de agentes externos (ou, pelo menos, com a possibilidade de reconhecê-las quando esporádicas). Por fim, é necessário decidir como avaliar a confiabilidade dos dados, como tratá-los para extrair informações efetivamente úteis e com que meios viabilizar a canalização desse conhecimento para os demais atores envolvidos na tarefa da conservação preventiva.

Contudo, constata-se que não existe um protocolo de como atuar universalmente reconhecido, mas, sim, uma série de estudos de casos reportados na literatura, frequentemente com vários pontos comuns e que podem inspirar a definição de formas de proceder, sem, contudo, que se possa falar ainda em modelos gerais e unívocos.

A seguir, pretende-se mostrar a aplicação de uma proposta de uma metodologia de diagnóstico microambiental a partir do estudo de caso de uma construção histórica da cidade de São Paulo. Trata-se da Casa de Dona Yayá, um casarão construído em várias etapas a partir do final do século XIX e localizado no bairro do Bexiga, na região central da capital paulista. Esse edifício, local do confinamento psiquiátrico forçoso de dona Sebastiana de Mello Freira la dona Yayá) durante mais de 40 anos (1920-19619191 e hoje propriedade da Universidade de São Paulo, se presta a um estudo de caso dessa natureza por duas ordens de razões. Primeiramente, por seu significado simbólico - já que a USP ali abriga o Centro de Preservação Cultural (CPC-USP) - e efetivo uso como espaço de preservação de acervo e de exposições culturais temporárias, logo exigindo cuidados de ordem ambiental. Em segundo lugar, devido à ausência de instalações de controle climático ou de quaisquer outros esquemas de mitigação ativa de pressões ambientais. Tal situação oferece o ensejo para uma análise isenta de distorções de partida, em que os componentes arquitetônicos da casa-museu e as modalidades de seu uso corriqueiro constituem os principais determinantes das características dos diversos microambientes ali presentes.

O diagnóstico do local (Figura 2) envolveu três parâmetros considerados potencialmente cruciais no contexto em que o casarão está inserido: microclima 
(temperatura e umidade), contaminação por bioaerossóis e presença de poluentes atmosféricos típicos do meio urbano.

\section{Diagnóstico microclimático}

Para o estudo microclimático, buscou-se adotar princípios norteadores propostos por autores consagrados ${ }^{92}$ e diretrizes sistematizadas no âmbito de consórcios cooperativos. ${ }^{93}$ Alguns estudos de caso específicos ${ }^{94}$ também serviram, nesse caso, para balizar as escolhas de aparelhos de monitoramento, suas especificações e configurações e locais de instalação. Os mesmos princípios gerais foram adotados nas formas de tratamento dos dados, ainda que nesse aspecto algumas escolhas tenham sido opção autônoma por parte dos autores, visando buscar respostas para determinadas questões, como foi o caso da análise dos dados climáticos por dia da semana.

Assim, optou-se por empregar, para as medidas de temperatura (T) e de umidade relativa (UR), dispositivos datalogger marca ONSET (USA), modelo U 1 O003 , dotados de sensores dos dois parâmetros com uma margem de erro (acurácia) de $0,5^{\circ} \mathrm{C}$ e 3,5\%, respectivamente. $\bigcirc$ fabricante apresentou certificado de calibração, o que, pelo período de um ano, constitui uma garantia aceitável de exatidão dentro das especificações dadas. Além disso, os aparelhos foram testados previamente no mesmo ambiente, apresentando valores de Te de UR discrepantes entre si dentro do mesmo intervalo de erro.
92. Ver Dario Camuffo (1998), Adriana Bernardi (2008) e Tim Padfield (s.d.).

93. Ver May Cassar e Jeremy Hutchings (2000) e Francesca Becherini et al. (2012).

94. Ver Dario Camuffo et al. (2002), Lukasz Bratasz, Dario Camuffo e Roman Kozlowski (2007), Stefano Paolo Corgnati, Valentina Fabi e Marco Filippi (2009) e Willi de Barros Gonçalves (2013).
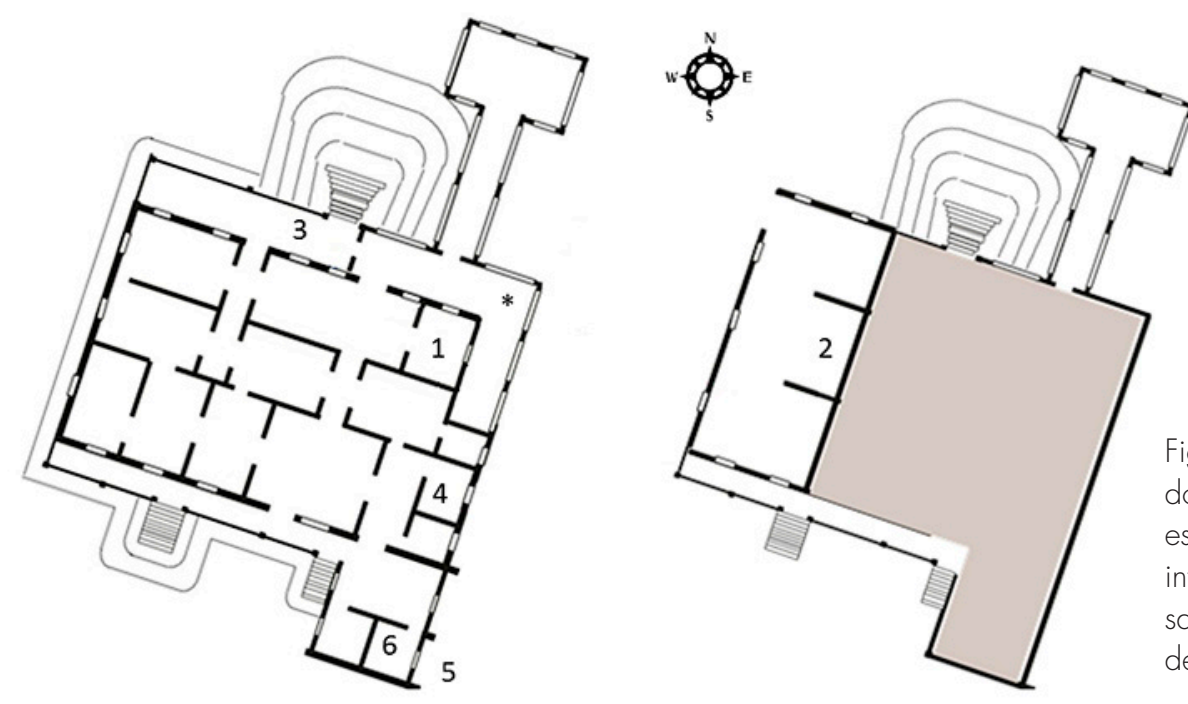

Figura 2 - Plantas atuais do pavimento principal là esquerda) e do pavimento inferior (à direita) da Casa de Dona Yayá. Fonte: desenhos dos autores. 
Escolheram-se dois locais de monitoramento: um espaço usado para as exposições, no pavimento principal da casa, indicado como ponto 1 na Figura 2 ("Sala Marrom", SM), e uma área no pavimento inferior, indicado como ponto 2 e usado para fins administrativos, mas proposto como possível localização, no futuro, de uma reserva técnica para o acervo do CPC ("Porão", PO). Um datalogger foi também instalado na área externa, no ponto 3, mas no final do programa seus dados foram descartados, pois não eram representativos do clima real do meio urbano, possivelmente por causa da influência da parede do casarão em que estava pendurado. Assim, para fins de comparação do microclima indoor com o clima da cidade de São Paulo, foram utilizados os dados climáticos fornecidos por sete estações de qualidade do ar da Companhia Ambiental do Estado de São Paulo (Cetesb), disponíveis na plataforma Qualar. ${ }^{95}$

Os resultados são constituídos por tabelas de valores horários de T e UR externos e dos dois microambientes interiores coletados ininterruptamente durante o período de 12 meses, de julho de 2013 a junho de 2014.

A Figura 3 e a Tabela 1 apresentam uma síntese geral dessas informações. Em particular, a Figura 3 mostra a tendência das duas grandezas por meio de curvas "alisadas" obtidas aplicando o método da média móvel nos 15 dias anteriores e posteriores a cada ponto. Esse procedimento permite anular graficamente as flutuações diárias e destacar o andamento médio anual desses fatores.
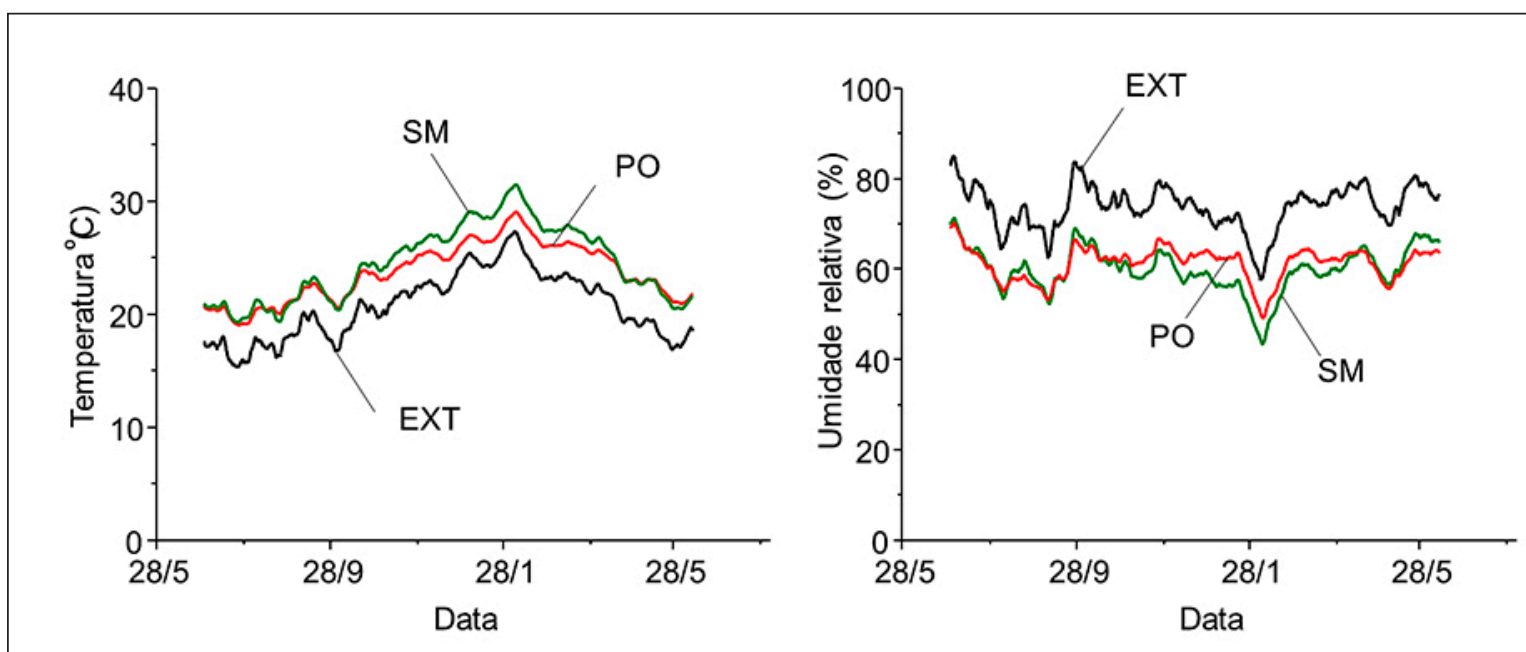

Figura 3 - Curvas que mostram a variação anual dos valores médios de temperatura do ar e de umidade relativa de dois locais internos (Sala Marrom e Porão) da Casa de Dona Yayá (fonte: dados primários desta pesquisa) comparados com os dados externos da cidade de São Paulo nos mesmos períodos (fonte: dados da Cetesb sistematizados pelos autores). 
Tabela 1 - Sumário dos principais parâmetros microclimáticos de dois locais internos (Sala Marrom e Porão) da Casa de Dona Yayá (fonte: dados primários desta pesquisa) comparados com os dados externos da cidade de São Paulo nos mesmos períodos. (fonte: dados da Cetesb sistematizados pelos autores).

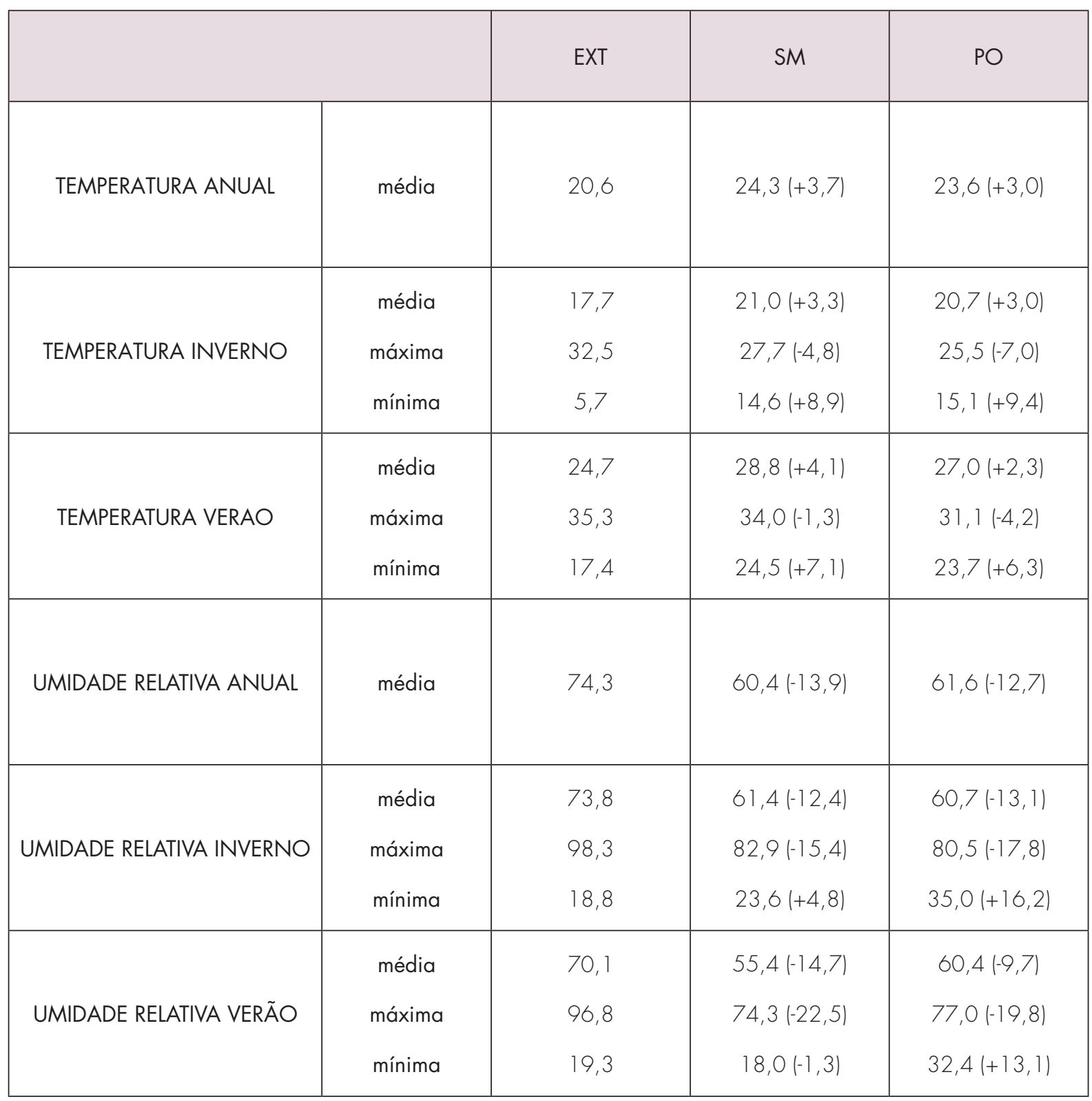


96. Ver Franciza Lima Toledo (2006).

No caso da temperatura, observam-se claramente a variação sazonal nos valores externos e o acompanhamento dessa curva pelas tendências dos microambientes internos, indicando que o clima local é o principal determinante do microclima indoor, fato inteiramente esperado. Contudo, o ambiente interior apresenta um regime térmico mais elevado, estando mediamente mais quente: $+3,7^{\circ} \mathrm{C}$ na SM e $+3,0^{\circ} \mathrm{C}$ no $\mathrm{PO}$. Essa diferença média está ligada à forma como o espaço interno responde às flutuações diárias da temperatura, mostrada em dois exemplos típicos do inverno e do verão na Figura 4. Nesta, repara-se que as curvas da SM e do $\mathrm{PO}$ seguem as oscilações do clima externo em amplitudes menores e próximas aos valores máximos, com os quais a curva da SM tende a coincidir no verão. Isso significa que os ambientes internos aquecem com facilidade durante o dia, mas apresentam certa inércia ao resfriamento durante a noite. Tal desempenho está ligado às características dos materiais de construção, a feições arquitetônicas nas quais a facilidade de penetração de radiação solar desempenha, sem dúvida, um papel importante e, finalmente, às formas de uso do imóvel, notadamente à abertura dos vãos durante o dia (facilidade de circulação de ar nas horas quentes) e seu fechamento durante a noite (impedimento da circulação de ar nas horas frias). O comportamento distinto da $S M$ perante o $P O$ no verão é sinal do efeito da exposição à radiação solar, maior nessa estação e direta no pavimento principal da casa, sobretudo do lado em que fica localizado a SM. O canto nordeste dessa sala é adjacente a um corredor mais externo em formato de L, apresentando vidraças não escurecidas voltadas para $\circ$ jardim que permitem irradiação direta de seu interior. Nesse corredor se cria um claro efeito de estufa (totalmente ausente no PO) com significativa retenção de calor. É provável que, para o comportamento microclimático da $\mathrm{SM}$, contribuam pelo menos duas alterações significativas na estrutura arquitetônica do casarão introduzidas ao longo do tempo: o pátio anexo construído na extremidade nordeste do terreno para os passeios confinados de dona Yayá e a substituição do assoalho da SM e das salas adjacentes por um piso de cimento. Toledo, 96 justamente, salienta como modificações desse tipo nas construções históricas são inseridas em épocas posteriores e, portanto, estão eventualmente em desacordo com os preceitos arquitetônicos originais, inclusive aqueles concebidos para controlar o microclima interno no tocante à temperatura e à umidade. A questão é que a capacidade térmica dos materiais e os padrões de circulação de ar exercem uma influência determinante no desempenho microclimático dos espaços interiores. No entanto, esses aspectos muitas vezes passam a ter uma importância secundária em face das demandas de outra natureza e, além do mais, a tendência atual é realizar o controle climático por meio de sistemas mecanizados, cuja real conveniência poderia ser assunto de uma discussão à parte. 

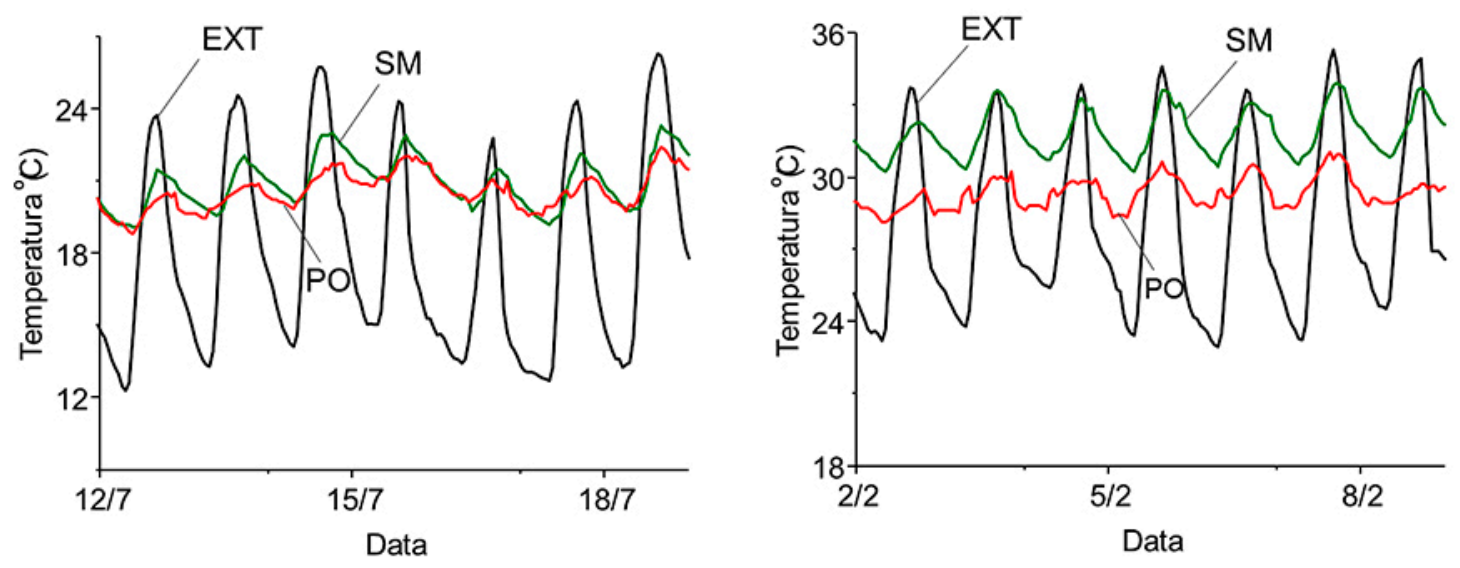

Figura 4 - Curvas que mostram exemplos do detalhamento referente a seis dias dos valores horários de temperatura do ar de dois locais internos (Sala Marrom e Porão) da Casa de Dona Yayá (fonte: dados primários desta pesquisa) comparados com os dados externos da cidade de São Paulo nos mesmos períodos (fonte: dados da Cetesb sistematizados pelos autores).

Por meio de histogramas de frequência (não mostrados), é possível confirmar que os horários de ocorrência das temperaturas máximas externas e internas apresentam boa sobreposição, estando concentrados ao redor das 16 horas em ambas as estações - efeito mais nítido para a SM no verão. As temperaturas mínimas externas predominam por volta das 6 horas, sem isso, porém, se constituir como um padrão claro nos ambientas internos, sobretudo no $\mathrm{PO}$ e no inverno, quando a ocorrência do mínimo diário chega a ser igualmente distribuída em praticamente todos os horários do dia. Vê-se assim que, em vários aspectos, $\mathrm{SM}$ e PO se configuram como microambientes distintos dentro da Casa de Dona Yayá, consideração que provavelmente se estende a outros espaços internos, em maior ou menor grau.

Usando o mesmo procedimento de cálculo de frequência aplicado aos dias da semana, foi possível elaborar o gráfico da Figura 5. Os diagramas estão apresentados na forma de contagem diferencial, isto é, cada barra corresponde à diferença de contagem de ocorrência, por dia da semana, das temperaturas mais elevadas entre o interior do museu e o exterior. Esse tratamento, que foi restrito a cerca de 10\% dos valores horários mais elevados de temperatura, implica que valores positivos indicam maior ocorrência das temperaturas mais elevadas no ambiente interior em relação à atmosfera exterior e que valores negativos apontam para uma maior ocorrência no ambiente outdoor. Pela figura, é claro que em ambos os locais o microambiente indoor apresenta sistematicamente episódios de 
maior temperatura interna em relação à externa no período de domingo a terçafeira. Esse padrão pode estar associado com a interrupção das atividades e o fechamento dos espaços no fim de semana, o que provoca menor taxa de troca de ar e maior acúmulo de energia térmica. De acordo com o pessoal do CPC, há, sim, eventos culturais nesses dias da semana na casa, mas eles tendem a se concentrar no sábado e nas dependências externas. Também ocorrem normalmente na estação quente e, de fato, o padrão do verão (não mostrado), ainda que parecido, é menos nítido. Ora, o fenômeno agora evidenciado constitui um exemplo de característica microclimática provocada por formas de uso e gestão dos espaços. A evidenciação dessa peculiaridade, que não representa em si e a priori uma característica negativa, pode servir para antecipar o efeito de maiores ou menores taxas de circulação de ar entre os ambientes interior e exterior caso elas venham a ser julgadas um elemento importante tanto na perspectiva da conservação como na de outros aspectos de funcionamento do casarão.

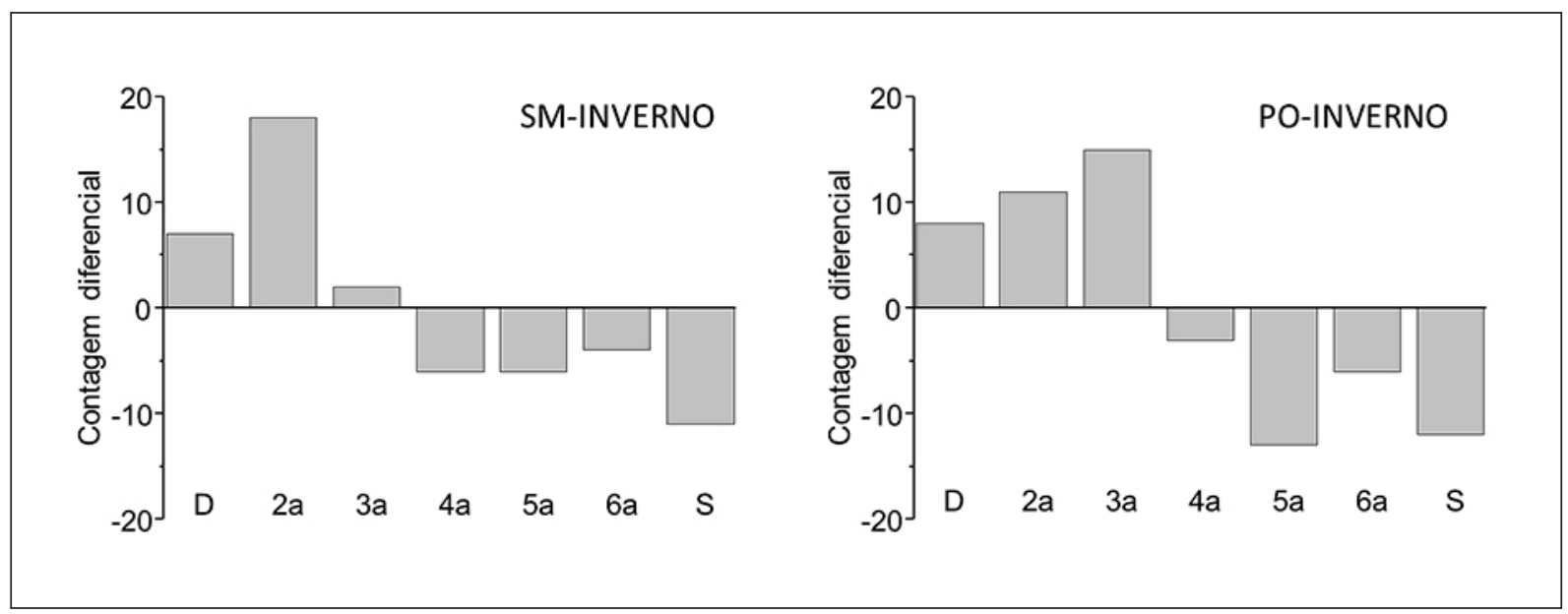

Figura 5 - Frequência de ocorrência das temperaturas mais altas (8\% dos valores mais elevados) nos diversos dias da semana na Sala Marrom (SM) e no Porão (PO) no período do inverno. Fonte: dados primários desta pesquisa.

Passando à análise das informações sobre umidade relativa, os dados primários foram tratados de maneira parecida aos da temperatura, resultando no quadro da tendência anual mostrado na Figura 3. Sua interpretação demanda uma consideração fundamental sobre essa grandeza, a dizer, o fato de que a UR depende de maneira direta da quantidade absoluta de vapor de água presente na atmosfera e é inversamente proporcional à temperatura do ar. Assim, dois aspectos desse gráfico podem ser salientados: primeiramente, a ausência de uma nítida discriminação de valores entre as duas estações extremas [com níveis indoor compreendidos na faixa de 70\% a 50\% e média anual de 60\% (SM) e 62\% (PO)] 
e, em segundo lugar, o descompasso sistemático entre umidade relativa externa e interna - essa última sempre mais baixa.

primeiro ponto se explica pelo fato de a queda da temperatura no inverno coincidir com a diminuição da taxa de precipitação, fenômeno típico do clima subtropical da cidade de São Paulo. Assim, esses dois fatores se compensam e isso leva a amenizar as variações de UR na passagem entre estações do ano. ${ }^{97}$ Consequentemente, pode-se dizer que o microclima interior se classifica como bastante úmido ao longo do ano inteiro, com todas as consequências previsíveis em relação à conservação dos materiais.

$\bigcirc$ segundo ponto parece decorrer principalmente do diferente regime térmico dos microambientes indoor. Ainda que, em ambas as salas, tenham sido constatadas concentrações absolutas de vapor de água frequentemente superiores aos valores externos, isso não chega a compensar o efeito da temperatura. Isso é corroborado pela leitura dos valores não filtrados de UR mostrados nos dois exemplos da Figura 6, similar aos análogos das temperaturas. Novamente, observam-se a resiliência dos microambientes interiores às variações noturnas (quando do aumento da umidade relativa) e a proximidade com a tendência diuturna (quando tipicamente ocorre a queda da UR).
97. Essa observação se aplica na média dos valores das duas estações principais, mas não exclui episódios de tempo seco, eventualmente drásticos e prolongados, decorrentes de aumento da temperatura sem precipitações - fato esse que não ocorreu no período examinado neste trabalho.

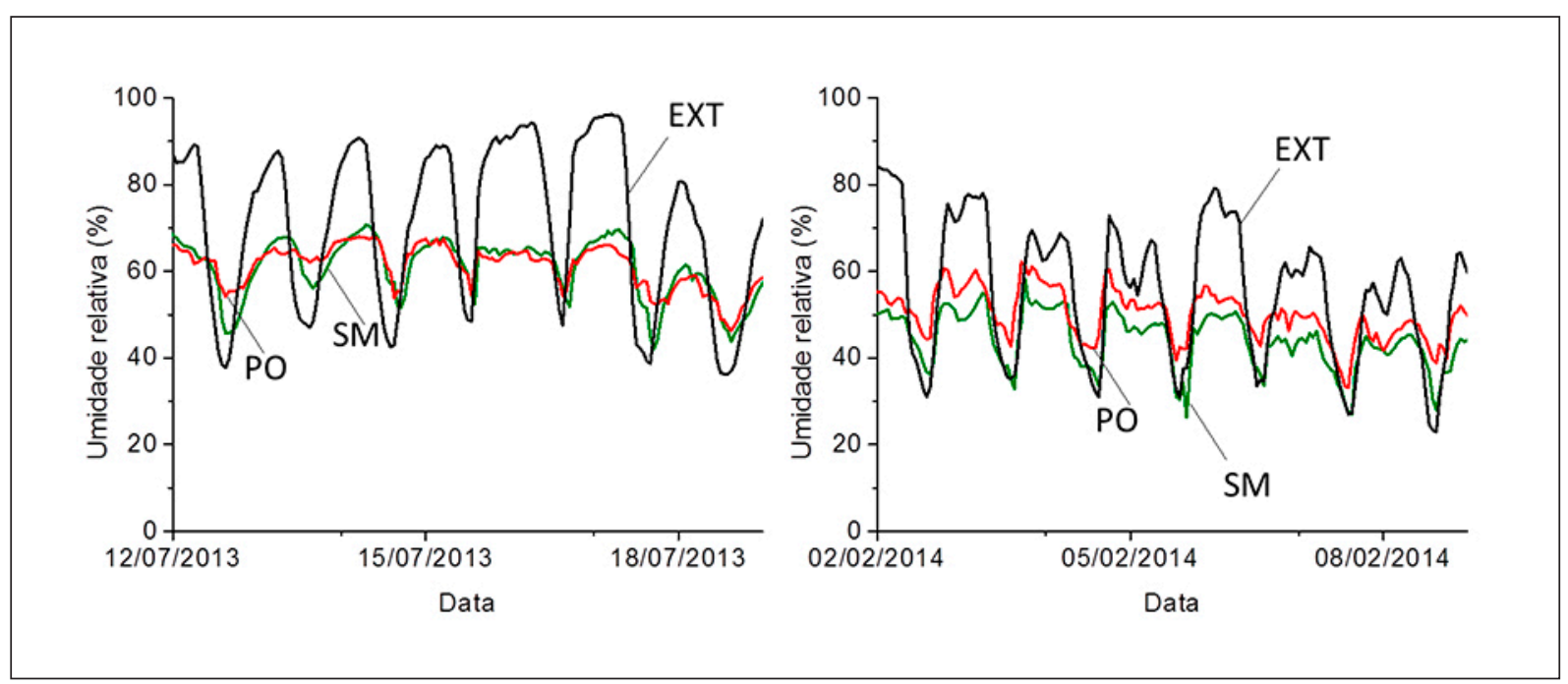

Figura 6 - Curvas que mostram exemplos do detalhamento referente a seis dias dos valores horários de umidade relativa do ar de dois locais internos (Sala Marrom e Porão) da Casa de Dona Yayá (fonte: dados primários desta pesquisa) comparados com os dados externos da cidade de São Paulo nos mesmos períodos (fonte: dados da Cetesb sistematizados pelos autores).

Assim, é possível sumarizar que os microambientes internos à edificação, conquanto sujeitos a variações de UR diretamente provocadas pela pressão 
98. Vale, contudo, destacar a excepcional estabilidade da umidade relativa média no PO.

99. Ver Dario Camuffo et al. (2004).

100. Ver Stefan Michalski (2014).

101. Cabe destacar que, para que um estresse mecânico possa ser significativo na escala diária, é necessário que o tempo de resposta do material à absorção de umidade seja curto, ou seja, que o material absorva umidade rapidamente.

102. Stefan Michalski (2014) denomina esse limite de proofed fluctuation. exercida pelo contexło climático externo, apresentam peculiaridades próprias e até distintas entre os dois espaços. Em particular, o acúmulo de energia térmica, provocando valores mais elevados de temperatura, é o maior responsável por amenizar os níveis de UR, já que a concentração absoluta de vapor de água é tendencialmente maior do que na atmosfera externa. Isso demonstra que a eventualidade de iniciativas voltadas para o controle da temperatura deveria ser cuidadosamente avaliada à luz dos impactos na umidade relativa e, provavelmente, prever ações de remoção ativa de vapor de água, uma vez que, no contexto subtropical, o risco de danos associados com a biodeterioração dos materiais é muito expressivo.

Uma última observação diz respeito às flutuações de UR, que também constituem um importante parâmetro microclimático na perspectiva da conservação preventiva. Na escala intersazonal, as diferenças nos valores de UR média são pouco expressivas, sendo de 6,0 e 0,3 unidades percentuais, respectivamente, na $\mathrm{SM}$ e no PO. Esse ponto, que reflete bastante o que acontece no mesoclima regional da região metropolitana de São Paulo (diferença intersazonal de UR igual a 3,7 unidades percentuais), é pouco específico das condições microclimáticas dos locais indoor do casarã $0^{98}$ e pode ser considerado um indicador bastante positivo.

Já as oscilações diárias, de curto prazo, mostram uma situação mais preocupante: as médias das amplitudes diárias de UR são de 15,0 e 11,0 unidades percentuais (perante um valor de 38 u.p. no ambiente externo). Uma forma interessante de avaliar o significado desse resultado foi proposta por Camuffo 99 e segue a linha de raciocínio adotada também por Michalski. ${ }^{100} \mathrm{~A}$ ideia é que os materiais contidos num determinado espaço de conservação ao longo do tempo se adaptaram ao estresse mecânico proporcionado pelas flutuações constantes de UR, eventualmente com a formação de rachaduras ou fissuras. A ocorrência regular de flutuações na mesma magnitude não deveria acrescentar novos danos significativos, a não ser que as propriedades mecânicas dos materiais sofram alterações (por exemplo, por conta de um processo de restauro). Ora, no caso dos dois ambientes da Casa de Dona Yayá, calculou-se estatisticamente a frequência de flutuações de UR e verificou-se que, na grande maioria dos dias do ano, a diferença entre os valores máximo e mínimo diários se concentra no valor de 12 u.p. para a SM e de 8 u.p. para o PO. A esse respeito, a metodologia de Camuffo sugere que se avalie com que frequência ocorrem oscilações diárias maiores que o dobro desses valores, pois tais ocorrências são as que realmente podem provocar danos expressivos aos materiais higroscópicos ${ }^{101}$ por ultrapassarem em 100\% o limite de flutuação ao qual os materiais daquele espaço estão "acostumados". 102 No caso da SM, esse limite foi ultrapassado 43 vezes no ano $(11,8 \%$ dos dias do ano) e no PO isso ocorreu 61 vezes (16,7\%). Um resultado 
como esse mostra que o PO, ainda que apresente flutuações diárias de UR mediamente menores que na SM, está sujeito a uma ocorrência maior de episódios de impacto mecânico nos materiais higroscópicos e, portanto, requer uma atenção maior na contenção de tais episódios. Uma análise de como a mitigação se daria, se julgada necessária em função do tipo e do estado do acervo, deveria ser objeto de uma discussão mais aprofundada, mas acredita-se que uma série de ações eficientes do ponto de vista dos resultados e dos custos laberturas de portas e janelas, ventilação dos ambientes) poderia ser desenvolvida a partir de processos de monitoramento em tempo real dos fluxos de energia e de ar entre os ambientes externo e interno.

\section{Diagnóstico microbiológico do ar}

diagnóstico microbiológico foi realizado no mesmo espírito metodológico de coleta e análise dos dados empregado por vários autores no contexto de edificações utilizadas para o abrigo de bens culturais, ${ }^{103}$ com adaptações inseridas em função das especificidades dos ambientes investigados e dos aparelhos disponíveis. A abordagem consistiu em quantificar a concentração de microrganismos suspensos no ar e foi baseada em duas medidas realizadas nos dias 25/9/2015 e 29/3/2016, isto é, antes e depois da estação chuvosa, para comparar o efeito da umidade relativa do ar. $\bigcirc$ diagnóstico foi realizado para a SM, o PO e uma sala identificada na Figura 2 como ponto 6 e que era usada, até a véspera da primeira medida (25/9/2015), para guardar o acervo do CPC. Essa sala foi, sucessivamente, usada para outra finalidade e, por esse motivo, foi excluída da segunda etapa de medidas.

A metodologia prevê coletar e contar unidades capazes de gerar uma colônia de fungos ou de bactérias ${ }^{104}$ em um dado volume de ar e isso se deu, no caso específico, aspirando mecanicamente o ar por meio de aparelho apropriado (no caso, usou-se o Spin Air da marca IUL S.A., USA), funcionando a uma vazão de 100 litros por minuto. $\bigcirc$ tempo de amostragem (e, consequentemente, o volume de ar amostrado) foi ajustado em quatro minutos (400 litros) para os fungos e dez minutos (1 1.000 litros) para as bactérias, valores fixados a partir de testes preliminares que indicaram as concentrações médias esperadas para esses locais. No aparelho, as unidades formadoras de colônias (UFCs) são impactadas sobre um disco de Petri de $90 \mathrm{~mm}$ de diâmetro no qual era previamente predisposto o meio de cultura à base de ágar e dextrose de batata (PDA) para fungos e de triptona e extrato de levedura (meio Luria Brentani, LB) para bactéria, de acordo com protocolos convencionais para essa finalidade. Após a coleta, os discos são vedados, levados
103. Ver Dario Camuffo et al. (2001), Kristin Gysels et al. (2004), Francesca Cappitelli et al. (2009), Cesira Pasquarella et al. (2012) e Justyna Skora et al. (2015).

104. Trata-se de células ou esporos individuais, ou agrupamentos destes que têm capacidade de, na presença de condições favoráveis, se multiplicar e gerar uma colônia de uma ou mais espécies de microrganismos. Essas unidades são chamadas unidades formadoras de colônias (UFCs ou colonies forming units, CFUs, em inglês) e sua quantificação constitui um procedimento comumente reportado na literatura para avaliar o grau de contaminação do ar em determinado ambiente. 
para o laboratório e incubados por tipicamente 48 horas a $25^{\circ} \mathrm{C}$, em condições aptas a evitar contaminação por microrganismos. Após o desenvolvimento, as colônias crescidas de fungos e bactérias são contadas e relacionadas ao volume de ar amostrado, resultando em concentrações de UFCs por $\mathrm{m}^{3}$, lançadas na Tabela 2. Na Tabela 3 são relatados indicadores das condições meteorológicas para a cidade de São Paulo obtidas de estações do Instituto Nacional de Meteorologia (Inmet) e da Cetesb e referentes aos períodos imediatamente anteriores às coletas.

Tabela 2 - Sumário das concentrações de unidades formadoras de colônias de fungos e de bactérias medidas no ambiente externo (EXT) à Casa de Dona Yayá e em três locais internos (Sala Marrom, Porão e Ponto 6) nos dias 25/9/2015 e 29/4/2016. Fonte: dados primários desta pesquisa.

\begin{tabular}{|c|c|c|c|c|c|}
\hline \multicolumn{2}{|c|}{} & EXT & SM & PO & PONTO 6 \\
\hline $\begin{array}{c}\text { UFC/m3 } \\
25 / 09 / 15\end{array}$ & fungos & $305 \pm 170$ & $250 \pm 12$ & $240 \pm 12$ & $115 \pm 17$ \\
\hline bactérias & $54 \pm 24$ & $26 \pm 11$ & $34 \pm 6$ & $24 \pm 5$ \\
$29 / 03 / 16$ & bactérias & $46 \pm 10$ & $58 \pm 10$ & $136 \pm 33$ & - \\
\hline
\end{tabular}

Tabela 3 - Sumário das condições meteorológicas anteriores ao período de coleta em setembro de 2015 e março de 2016 : temperatura (T), umidade relativa (UR), velocidade do vento (W), concentração externa de ozônio $\left(\left[\mathrm{O}_{3}\right]\right.$ ), radiação solar global (RADG) e radiação ultravioleta (RADUV) médios no período de dois meses e precipitação acumulada no períodos de dois meses (PPT2) e de dez dias (PPT 10). Fonte: dados do Inmet e da Cetesb sistematizados pelos autores.

\begin{tabular}{|c|c|c|c|c|c|c|c|c|}
\hline & $\mathrm{T}\left({ }^{\circ} \mathrm{C}\right)$ & UR $(\%)$ & $\mathrm{VV}(\mathrm{m} / \mathrm{s})$ & $\mathrm{O}_{3}(\mathrm{ppb})$ & $\begin{array}{c}\text { RADG } \\
\left(\mathrm{W} / \mathrm{m}^{2}\right)\end{array}$ & $\begin{array}{c}\text { RADUV } \\
\left(\mathrm{W} / \mathrm{m}^{2}\right)\end{array}$ & $\begin{array}{c}\text { PPT 2 } \\
(\mathrm{mm})\end{array}$ & $\begin{array}{c}\text { PPT10 } \\
(\mathrm{mm})\end{array}$ \\
\hline Setembro & 20,0 & 66,0 & 2,0 & 15,4 & 160 & 8 & 194,3 & 0,0 \\
Março & 23,9 & 75,7 & 2,4 & 15,5 & 183 & 12 & 553,9 & 28,1 \\
\hline
\end{tabular}


Posteriormente, as colônias formadas a partir das UFCs são isoladas de maneira a possibilitar o crescimento de cepas puras em meio de cultura e a diferenciação das diversas espécies pelas características morfológicas macroscópicas. Sucessivamente, as espécies de fungos mais abundantes são testadas para verificar sua capacidade "celulolítica", a dizer, de digerir celulose através do ensaio do vermelho congo, ${ }^{105}$ com o intuito de estabelecer seu potencial de agressão sobre objetos de madeira e à base de papel, que frequentemente (mas não exclusivamente) representam o principal alvo da biodeterioração. Salientase que, num estudo focado nesse tipo de risco de dano ao patrimônio material, essa abordagem poderia ser aprofundada de várias maneiras, seja aprimorando os procedimentos de coleta dos microrganismos, seja buscando a identificação precisa das espécies isoladas lo que, hoje em dia, é feito por técnicas de sequenciamento do DNA), seja ainda investigando com maior precisão os mecanismos bioquímicos por trás da degradação dos materiais e, portanto, o espectro de ação desses agentes.

Os dados coletados no casarão de dona Yayá mostram que as contagens de microrganismos totalizaram quantidades médias de fungos entre $115 \mathrm{UFCs} / \mathrm{m}^{3}$ e 250 UFCs $/ \mathrm{m}^{3}$ no fim do inverno e $57 \mathrm{UFCs} / \mathrm{m}^{3}$ e $97 \mathrm{UFCs} / \mathrm{m}^{3}$ no fim do verão, enquanto as bactérias apresentaram valores de $24 \mathrm{UFCs} / \mathrm{m}^{3}$ a $34 \mathrm{UFCs} / \mathrm{m}^{3}$ e 58 UFCs $/ \mathrm{m}^{3}$ a $136 \mathrm{UFCs} / \mathrm{m}^{3}$, respectivamente, nos mesmos dois períodos de coleta. Tais valores podem ser considerados, de um modo geral, moderados se comparados com os dados disponíveis na literatura sobre arquivos, bibliotecas e museus. Por exemplo, em estudo de $1999^{106}$ no Sainsbury Centre for Visual Arts (SCVA), em Norwich (Inglaterra), as concentrações de bactérias alcançam valores que vão desde 160 UFCs $/ \mathrm{m}^{3}$ (inverno) até mais que 600 UFCs $/ \mathrm{m}^{3}$ (verão). No caso dos fungos (tidos como mais agressivos nos processos de biodeterioração de bens culturais), tais níveis se limitam à faixa de $7 \mathrm{UFCs} / \mathrm{m}^{3}$ a $26 \mathrm{UFCs} / \mathrm{m}^{3}$. Já em trabalho referente ao arquivo histórico da $\mathrm{Ca}^{\prime}$ Granda de Milão, ${ }^{107}$ as bactérias alcançaram a faixa de 300-1.000 UFCs/m³, e os fungos, a faixa de 500-800 UFCs $/ \mathrm{m}^{3}$, valores que tendem a piorar no período pós-meridiano e no pavimento inferior da edificação. Estudo parecido e recente em museus, arquivos e bibliotecas da Polônia ${ }^{108}$ indica valores tendencialmente mais elevados de bactérias e fungos - estes últimos com medidas superiores ou próximas a 1.000 UFCs $/ \mathrm{m}^{3}$ em cinco das oito instituição monitoradas. Cabe mencionar que uma diretriz do Ministério dos Bens Culturais da Itália ${ }^{109}$ recomenda, para essas duas categorias de microrganismos, níveis máximos de $750 \mathrm{UFCs} / \mathrm{m}^{3}$ (bactérias) e $150 \mathrm{UFCs} / \mathrm{m}^{3}$ (fungos). No caso, ambos os microambientes da Casa de Dona Yayá monitorados (PO e SM) ultrapassaram o padrão recomendado para fungos nas medidas realizadas em setembro de 2015.
105. Ver Felipe Sousa Neves Andrade (2016).

106. Ver Peter Brimblecombe et al. (1999).

107. Ver Francesca Cappitelli et al. (2009)

108. Ver Justyna Skora et al. (2015).

109. Ver Francesca Cappitelli et al. (2009). 
110. Ver Che Fengxiang et al. (1991), Francis Nussbaum (1991) e Abdel Hameed et al. (2009).
Ora, é claro que a comparação com os estudos citados serve meramente para orientar a leitura dos dados coletados, visto que as instituições mencionadas não somente apresentam características completamente distintas das da Casa de Dona Yayá - são todos espaços de conservação ou exibição de artefatos históricos e culturais e, portanto, ricos de substrato para o desenvolvimento dos microrganismos - como estão inseridas em contextos climáticos e micro/ macroambientais totalmente diferentes. A título de exemplo, as coletas realizadas no SCVA chegaram a apresentar taxas externas nulas (fungos) ou muito baixas (bactérias) no inverno quando comparadas às do verão. Ou seja, a flutuações térmicas nas regiões do clima temperado parecem ser suficientemente drásticas para influenciar nos níveis de microrganismos no ar, ao passo que essa influência nos climas tropicais tende a não ser muito significativa. No caso da cidade de São Paulo, isso pode ser observado nas medidas externas realizadas nos dois períodos deste estudo: o final do inverno mostrou concentrações outdoor de fungos três vezes mais altas do que o final do verão. No caso das bactérias, a diferença foi de $+20 \%$, sempre a favor do período mais frio. Entretanto, os dados meteorológicos mostram que as diferenças médias de temperatura e de UR foram apenas de aproximadamente 4oC e 10\%, respectivamente. Assim, nesse intervalo de variação de temperatura e umidade do ar, acredita-se que as diferenças sazonais nas concentrações de microrganismos possam ser explicadas mais à luz da influência da incidência de radiação solar e da luz ultravioleta (Tabela 3), as quais podem ter um efeito inibidor no crescimento de microrganismos, ${ }^{110}$ e das precipitações chuvosas (IDEM) atuando no processo de limpeza de material suspenso no ar, inclusive germes e esporos. Nesse sentido, os dados apresentados na Tabela 3 apontam claramente para condições meteorológicas mais favoráveis ao acúmulo de microrganismos no período em que efetivamente houve coletas mais abundantes de fungos e de bactérias.

Em relação aos ambientes indoor, observa-se que as concentrações dos fungos refletem de perto as concentrações outdoor, com níveis mais baixos tanto no inverno como na primavera, conforme mostra a Figura 7. É interessante que o local com as maiores concentrações de fungos seja aquele que menos apresenta condições favoráveis ao seu desenvolvimento, pois tanto o PO como a sala do Ponto 6, a rigor, seriam locais com maior predisposição à proliferação desses microrganismos (o Ponto 6 corresponde à sala onde era conservado o acervo do CPC até o dia da coleta, e o Porão apresenta um extenso sistema de madeiramento). Esse fato parece reforçar que outros fatores controlam a disponibilidade de unidades formadoras de colônias de fungos e, provavelmente, a ventilação e outros aspectos facilitadores do acesso de microrganismos de origem externa devem ser mais determinantes, pelo menos nas atuais condições da Casa de Dona Yayá. 


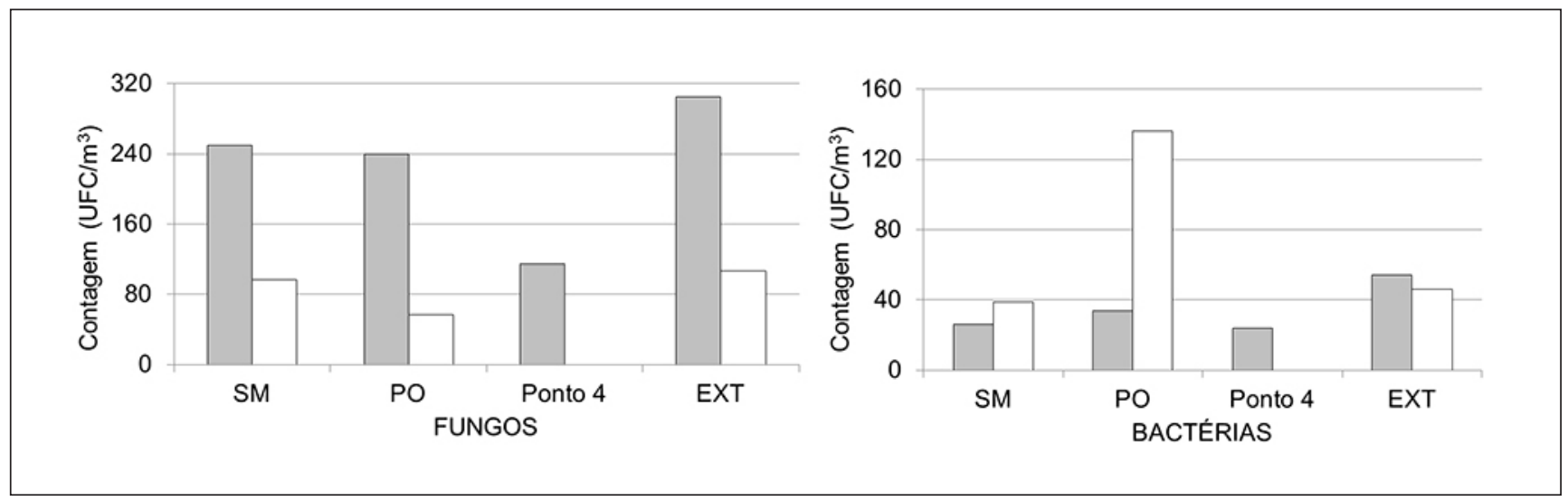

Figura 7 - Concentrações médias de unidades formadoras de colônias de fungos e de bactérias medidas no ambiente externo (EXT) à Casa de Dona Yayá e em três locais internos (Sala Marrom, Porão e Ponto 6) nos dias 25/9/2015 e 29/4/2016. Fonte: dados primários desta pesquisa.

De todos os fungos coletados nos locais indoor, as 27 cepas mais recorrentes ${ }^{111}$ foram testadas quanto à atividade celulolítica (conforme explicado acima) e $85 \%$ delas deram resultado positivo, indicando que são potencialmente danosas para os substratos que contêm celulose, como papel, madeira e algodão. No ambiente externo, onde a variedade de fungos foi menor (oito são os fungos mais recorrentes), a proporção de fungos com atividade celulolítica é reduzida a 50\%. Esse resultado mostra que, ainda que haja menor quantidade absoluta de UFCs nos locais internos, na prática, o potencial de impacto ali é maior, pois o próprio ambiente apresenta condições microclimáticas e, provavelmente, de disponibilidade de nutrientes, que discriminam a favor dos microrganismos mais prejudiciais.

Com relação às bactérias, a diferença entre as concentrações externas nos dois períodos de amostragem foi pouco expressiva e novamente se destaca a tendência a uma maior presença de agentes biológicos dispersos no ar externo do que nos ambientes indoor, fato que indica que, no caso das bactérias, como no dos fungos, não parece haver fatores específicos para o desenvolvimento exacerbado no interior do casarão. O monitoramento de abril no PO mostrou um pico bastante inusitado que não foi possível justificar nem confirmar até o momento. Não representa necessariamente um problema específico, podendo até estar relacionado a fatores humanos, mas constitui um possível sinal de alarme e claramente precisaria ser investigado em maior profundidade e, idealmente, com adequadas ferramentas de caracterização desse tipo de microrganismo.

111. Isto é, aquelas cepas que, em cada placa de amostragem, apresentavam uma quantidade de UFCs igual ou superior a $50 \%$ do total das UFCs da mesma placa. 


\section{Diagnóstico da qualidade do ar: concentrações de ozônio}

Um adequado diagnóstico da qualidade do ar do ponto de vista da presença de polventes potencialmente prejudiciais à estabilidade dos materiais deveria, em princípio, contemplar toda a variedade de componentes químicos enumerados no item 2.4 deste trabalho. Essa tarefa seria extremamente trabalhosa e onerosa financeiramente e se justificaria somente no caso de haver, no local interessado, artefatos de importante valor cultural e de especial vulnerabilidade. No caso da edificação em exame, ademais, não há indicativos de possíveis fontes internas de poluentes e, portanto, o diagnóstico tem que focar especificamente o exame da tendência à penetração de polventes de origem externa. Por esse motivo, é importante conhecer quais ameaças de natureza química são encontradas no contexto regional e definir um plano de monitoramento centrado nelas.

No específico, as características da qualidade do ar da cidade de São Paulo são bem conhecidas pelos especialistas, por conta do amplo esquema de monitoramento implantado pela Cetesb. Sabe-se, assim, que o fenômeno chamado smog fotoquímico constitui o principal problema de poluição do ar, que seus principais componentes são o material particulado e o ozônio, tratados anteriormente, e que ambos estão relacionados à intensidade de emissão das fontes veiculares, embora segundo mecanismos bastante diferentes. Por essa razão, a estratégia de diagnóstico pode focalizar o ozônio, razoavelmente tomado como marcador da poluição outdoor, inclusive em função da possibilidade de usar os dados da Cetesb como sistema de referência das informações coletadas indoor.

Neste trabalho, o ozônio foi monitorado de forma contínua por períodos consecutivos de alguns dias (e, portanto, não simultaneamente) no interior de três cômodos do casarão (ponto 2, PO, de 30/10/2012 a 8/1 1/2012; ponto 4, de 3/1/2012 a 19/12/2012; e ponto 6, de 20/1 1/2012 a 3/12/2012) e externamente, no local indicado como ponto 5 (de 8/1 1/2012 a 20/1 1/2012), conforme consta na Figura 2. As medidas não puderam ser efetuadas na SM (ponto 1) devido ao transtorno que causaria a instalação de um equipamento de médio porte e barulhento numa área de exposição, mas considera-se que as observações nos demais locais são passíveis de ser estendidas, com as devidas ressalvas, para o salão já caracterizado do ponto de vista climático e microbiológico. No caso do ponto 5, o aparelho foi instalado no local interior, mas com o duto de captação do ar projetado para fora do prédio através de uma janela. Esses pontos mostram aspectos práticos que, dependendo do tipo de medidas a serem realizadas, do grau de precisão, da extensão do monitoramento, entre outros, objetivamente limitam a liberdade de ação num processo de diagnóstico e precisam ser levados 
em consideração, harmonizando-os com as demais atividades e exigências da instituição. Por outro lado, as soluções adotadas para viabilizar as análises necessitam sempre de avaliações criteriosas com relação às eventuais interferências, nem sempre óbvias, nos valores medidos.

A concentração de ozônio foi obtida por meio de um instrumento específico (modelo 49i Ozone Analyzer da marca Thermo Scientific), que representa uma das melhores opções disponíveis quanto aos requisitos de precisão, exatidão, capacidade de detecção de baixos níveis de polvente, robustez, frequência de amostragem, só para citar os principais. Contudo, é uma máquina de custo elevado e não pensada para ter muita flexibilidade de uso. $\bigcirc$ aparelho, por meio de uma mangueira de material inerte, aspira o ar para dentro do sistema de detecção e armazena valores de concentração de ozônio tipicamente a cada 10 segundos, os quais são convertidos em médias horárias que representam os dados efetivamente empregados na caracterização do ambiente. Tais médias estão diagramadas em função do tempo no gráfico A da Figura 8. Na Figura 8B, estão representadas as concentrações horárias de ozônio medidas durante o mesmo período de tempo na região central da cidade de São Paulo pela Cetesb e resgatadas do banco de dados já citado no item 3.1. Essa informação é importante para interpretar os dados das concentrações indoor, visto que a atmosfera externa é a principal, se não a única, fonte desse polvente nos microambientes interiores.

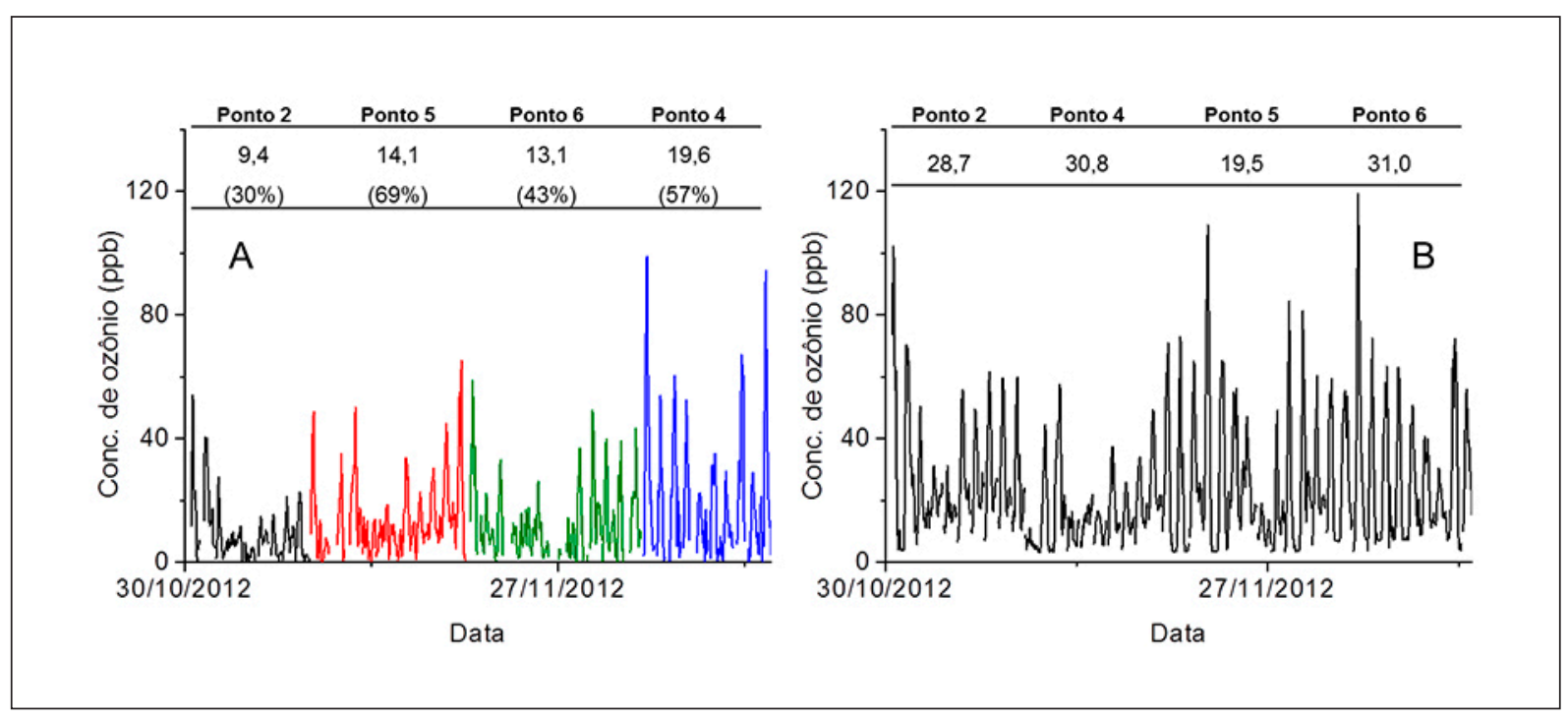

Figura 8 - Curvas que mostram as concentrações de ozônio em três locais internos da Casa de Dona Yayá em períodos sequenciais ( $A$, fonte: dados primários desta pesquisa) e na estação de monitoramento do Parque Dom Pedro II nos mesmos períodos (B, fonte: dados da Cetesb sistematizados pelos autores). Acima dos gráficos estão indicados os valores médios de cada período e, no caso do monitoramento dos ambientes da Casa de Dona Yayá, as razões entre as concentrações internas e as concentrações médias externas (razões i/o, entre parênteses). 
112. Ver Andréa Cavicchioli, Ravi Orsini Camargo de Souza e Guilherme Ranieri Reis (2013).

113. Ver Jean Tétreault (2003), que sugere um padrão de, no máximo, 5 ppb. Já Garry Thomson (1986) segue a linha da menor concentração possível e, portanto, para ele, tem que se atingir a melhor condição ditada pela necessidade (tipo de coleção) e pelas possibilidades de implementação.

114. Poderia, também, ser mais branda, mas um estudo anterior mostrou que é razoável esperar uma média anual de 10-15 ppb em locais com alta taxa de penetração de ozônio. A esse respeito, ver Andréa Cavicchioli, Ravi Orsini Camargo de Souza e Guilherme Ranieri Reis (2013).

115. Os relatórios anuais da Cetesb sobre a qualidade do ar evidenciam com clareza que em São Paulo é comum haver, especialmente em determinadas épocas do ano (por exemplo, abril e setembro), episódios prolongados de seca e de piora no índice de qualidade do ar.
Os resultados do monitoramento de ozônio indicam claramente presença expressiva desse poluente em todos os locais da Casa de Dona Yayá, em níveis atenuados em relação à poluição medida nas estações da Cetesb. Normalmente, conforme mostrado na tabela da Figura 8A, a concentração interna atinge níveis que representam entre $30 \%$ e $57 \%$ a concentração da estação de monitoramento de referência usada, fato normalmente sempre observado em situações como essa, $^{112}$ uma vez que o ozônio é um gás muito instável e reativo e tende a ser consumido no processo de transferência para os locais internos. Contudo, no período monitorado, todas as concentrações internas médias ficaram acima de 10 ppb (tabela da Figura 8A) e, dessa forma, ultrapassaram o padrão de qualidade recomendado por vários autores com relação a ambientes de conservação. ${ }^{113}$ Essa ocorrência é inevitável, no caso de estudo analisado, se for considerada a ausência de medidas de contenção, e pode, em determinadas épocas do ano, se tornar mais acentuada em função de taxas mais elevadas de polvição urbana. ${ }^{114}$ A esse respeito, é muito significativa a constatação de que todos os ciclos diários de polvição externa (Figura 8B) são concomitantes aos ciclos de polvição por ozônio no interior da Casa de Dona Yayá, e isso pode servir para justificar o uso dos dados oficiais da Cetesb como instrumento para prever situações de crise na qualidade do ar externo (e, portanto, interno) e para disparar ações emergenciais de controle ambiental em determinados períodos do ano. ${ }^{115}$

\section{Avaliação do diagnóstico}

procedimento diagnóstico descrito nos parágrafos anteriores mostra um contexto microclimático no interior da edificação estudada, determinado, em grande medida, pelas condições climáticas do meio urbano em que ela está inserida. Alguns aspectos são particularmente representativos dessa interdependência, como o regime higrotérmico geral, as variações sazonais na quantidade de microrganismos dispersos no ar e a presença de polventes produzidos pelas atividades antrópicas externas. Contudo, foram evidenciadas várias características peculiares do ambiente indoor e, às vezes, de cada sala que foi objeto da investigação. Tais características são decorrentes dos atributos arquitetônicos da construção e do uso de seus espaços. Entre essas especificidades, foram destacados: i) temperaturas mediamente mais elevadas; ii) maior conteúdo de umidade absoluta associado a níveis mais moderados de umidade relativa; iii) tendência ao acúmulo de calor em determinados dias da semana; iv) amenização nas flutuações diárias de UR em relação à atmosfera outdoor; v) redução da presença de agentes microbiológicos no ar, ainda que acoplada com uma maior 
biodiversidade; e vil abatimento parcial da concentração de ozônio em relação aos níveis urbanos.

As implicações do quadro aqui delineado em termos de conservação preventiva, assim como as possíveis respostas no tocante à gestão dos espaços, irão sobretudo depender dos objetivos finais a serem alcançados, ${ }^{116}$ bem como da capacidade de implementação e manutenção dos programas e das ações de controle microambiental.

No entanto, cabe aqui destacar que o mapeamento de dados realizado revela tanto uma série de fatores de vulnerabilidade como um conjunto de potencialidades. A vulnerabilidade decorre de questões em que parece haver pouca ou nenhuma governança, como a inserção da edificação de determinado contexto geográfico (meio urbano e clima subtropicall); o tombamento da edificação e, consequentemente, as limitações nas opções de alteração arquitetônica; a presença de vegetação nas imediações da construção; o seu uso como local de trabalho e de lazer. Já as potencialidades consistem essencialmente nas opções oferecidas pela estrutura da edificação da Casa de Dona Yayá com relação ao controle passivo do microclima indoor, isto é, dispensada a instalação de um sistema mecanizado de ar condicionado, o que se harmonizaria com outras eventuais medidas de qualidade do ar, como sistemas de supressão de polventes químicos (scavengers) ou de contaminantes microbiológicos.

\section{CONSIDERAÇÕES FINAIS}

Compreender o conceito de microambientes, conseguir identificá-los em suas diversas escalas e desenvolver e implementar procedimentos adequados que permitam evidenciar neles as dinâmicas espaço-temporais dos agentes circunstantes de agressão constituem os primeiros passos da conservação preventiva dos bens culturais materiais. A partir dessa premissa e dos conhecimentos disponíveis hoje em dia sobre a influência dos vários parâmetros ambientais na lenta e progressiva degradação dos materiais, realizou-se um conjunto de operações de mediação voltadas para o diagnóstico (micro)ambiental do casarão histórico Casa de Dona Yayá, no centro da cidade de São Paulo.

A avaliação de duas áreas bastante distintas da edificação - empregandose esquema de diagnóstico que não foi, nem pretendeu ser, fechado e exaustivo - evidenciou a existência, ao mesmo tempo, de aspectos potencialmente favoráveis e desfavoráveis para a conservação de bens culturais. Entre eles, cabe destacar uma razoável estabilidade microclimática na ausência de sistemas mecanizados
116. Faz-se necessário reconhecer que, de acordo com os argumentos apresentados nas primeiras partes deste trabalho, o diagnóstico teria logrado maior eficácia se desenhado em função de objetivos específicos apresentados pela instituição, o que não ocorreu, devido à natureza ainda bastante acadêmica do estudo de caso empreendido. 
de intervenção, tais como ar-condicionado, aparelhos de desumidificação etc. (fator favorável), e uma forte pressão do macrocontexto em que a construção está inserida, exercida pela presença de bioaerossóis e, sobretudo, de polventes químicos de origem urbana (fator desfavorável).

Outras formas de proceder no mapeamento das informações eram cabíveis, outros aspectos poderiam ter sido avaliados para o delineamento de um quadro mais completo e outras interpretações para responder a perguntas específicas direcionadas à conservação patrimonial estavam ao alcance graças à quantidade de dados recolhidos. Das opções que foram feitas no modelo adotado, merecem ser salientadas, por um lado, a preocupação com a relação entre os microambientes internos e o ambiente externo e, por outro, a busca de associações (destacadas no decorrer da discussão) entre as características ambientais, as peculiaridades da edificação e a gestão do uso da estrutura do casarão.

A próxima etapa da estratégia geral de conservação preventiva consistiria em quantificar, ainda que de forma aproximada, o risco de dano decorrente da situação que foi delineada pelo diagnóstico e definir um plano de ações de mitigação, mas sua concepção dependeria de outro conjunto de análises: sobre a tipologia dos materiais dos bens conservados, seu estado atual de conservação/ desgaste e as possibilidades de atuação oferecidas tanto pela estrutura arquitetônica da edificação como pelas características financeiras e gerenciais da instituição ali abrigada.

Tal discussão e reflexão constituem o objeto de uma pesquisa de outra natureza e de outro porte. Contudo, acredita-se que esse momento não possa dispensar pelo menos três elementos: um olhar capaz de evidenciar as inter-relações entre os fatores ambientais, uma postura crítica com relação a soluções pautadas em receitas simplistas, muito drásticas e/ou puramente tecnológicas aos problemas e, finalmente, uma atitude constantemente alerta para o acompanhamento das respostas dos microambientes construídos a qualquer ação implementada. 


\section{REFERÊNCIAS}

LIVROS, ARTIGOS E TESES

ABDEL HAMEED, Awad, et al. Diurnal distribution of airborne bacteria and fungi in the atmosphere of Helwan area, Egypt. The Science of the Total Environment, v. 407, p. \62176222, 2009.

ALLSOPP, Dennis; SEAL, Kenneth; GAYLARDE, Christine. Introduction to Biodeterioration. Cambridge: Cambridge University Press, 2004.

ANDRADE, Felipe Sousa Neves. Estudo do impacto potencial das mudanças climáticas na biodeterioração de estruturas de madeiras no patrimônio cultural edificado do Vale Histórico Paulista. Dissertação (Mestrado) - Escola de Artes, Ciências e Humanidades, Universidade de São Paulo, São Paulo, 2016. 121 f.. Disponível em: <http://www.teses.usp.br/teses/ disponiveis/100/100134/tde-22082016-112924/pt-br.php>. Acesso em: 9 set. 2016.

ASHLEY-SMITH, Jonathan. Risk Assessment for Object Conservation. Oxford: ButterworthHeinemann, 1999.

ASHRAE - AMERICAN SOCIETY OF HEATING, REFRIGERATING AND AIR-CONDITIONING ENGINEERS. Museums, galleries, archives, and libraries. In: Handbook - Heating, Ventilating, and Air-Conditioning Applications. Atlanta: SI Edition, 2011.

BAER, Norbert Sebastian. Assessment and management of risks to cultural property. In: BAER, Norbert Sebastian; SABBIONI, Cristina; SORS, André. Science, Technology and European Cultural Heritage. Proceedings of the European Symposium. Guilford: Butterworth-Heinemann:, 1991, p. 27-36.

; BANKS, Paul. Indoor air pollution: effects on cultural and historic materials. International Journal of Museum Management and Curatorship, v. 4, n. 1, p. 9-20, mar. 1985.

BECHERINI, Francesca; BERNARDI, Adriana; BONAZZA, Alessandra; LÓPEZ-APARICIO, Susana; OZGA, Izabela Evaluation of climate. In: STRLIC, Matja; MATTAROZZI, Sandra (Ed.). Guidelines for Air Pollution Evaluation, Monitoring and Mitigation in Preventive Conservation of Cultural Heritage (TeACH Project). Bruxelles: The European Commission, 2012, p. 9-12. 
BERGSTEN, Carl-Johan; ODLYHA, Marianne; JAKIELA, Slawomir; SLATER, Jonathan; CAVICCHIOLI, Andrea; DE FARIA, Dalva Lúcia Araújo; NIKLASSON, Annika; SVENSSON, JanErik; BRATASZ, Lucasz; CAMUFFO, Dario; DELLA VALLE, Antonio; BALDINI, Francesco; FALCIAI, Riccardo; MENCAGLIA, Andrea; SENESI, Folco; THEODORAKOPOULOS, Charis Sensor system for detection of harmful environments for pipe organs (SENSORGAN). E-Preservation Sci., v. 7, p. 116-125, 2010. Disponível em: <http://www.morana-rtd.com/epreservationscience/2010/Bergsten-09-08-2010.pdf>. Acesso em: 9 set. 2016.

BERNARDI, Adriana. Microclimate Inside Cultural Heritage Buildings. Padova: Il Prato, 2008.

BRIMBLECOMBE, Peter. The composition of museum atmospheres. Atmospheric Environment, v. 1 , p. $1-8,1990$.

; BLADES, Nigel; CAMUFFO, Dario; STURARO, Giovanni; VALENTINO, Antonio; GYSELS, Kristin; VAN GRIEKEN, René; BUSSE, Hans-Jurgen; KIM, Oliver; ULRYCH, Ursula; WIESER, Monika. The indoor environment of a modern museum building, the Sainsbury Centre for Visual Arts. Indoor Air, vol. 9, n. 3, p. 146-164, sep. 1999.

; LANKESTER, Paul. Long-term changes in climate and insect damage in historic houses. Studies in Conservation, v. 58, p. 13-22, 2013.

CAMUFFO, Dario; BERNARDI, Adriana; STURARO, Giovanni; VALENTINO, Antonio. The microclimate inside the Pollaiolo and Botticelli rooms in the Uffizi Gallery, Florence. Journal of Cultural Heritage, v. 3, p.155-161, 2002.

; PAGAN, Emanuela; BERNARDI, Adriana; BECHERINI, Francesca. The impact of heating, lighting and people in re-using historical buildings: a case study. Journal of Cultural Heritage, v. 5, p. 409-416, 2004.

; VAN GRIEKEN, René; BUSSE, Hans-Jürgen; STURARO, Giovanni; VALENTINO, Antonio; BERNARDI, Adriana; BLADES, Nigel; SHOOTER, David; GYSELS, Kristin; DEUTSCH, Felix; WIESER, Monika; KIM, Oliver; ULRYCH, Ursula.. Environmental monitoring in four European museums. Atmospheric Environment, v. 35, n. 1, p. S127-S140, 2001.

BLADES, Nigel; ORESZCYN, Tadj; BORDASS, Bill; CASSAR, May. Guidelines on Pollution Control in Heritage Buildings. Londres: University College of London, 2000. Disponível em: <http://discovery.ucl.ac.uk/2443/1/2443.pdf>. Acesso em: 9 set. 2016.

BRATASZ, Lukasz; CAMUFFO, Dario; KOZLOWSKI, Roman. Target microclimate for preservation derived from past indoor conditions. In: PADFIELD, Tim; BORCHERSEN, Karen (Ed.). Contributions to the Copenhagen Conference Museum Microclimates. Copenhagen: The 
National Museum of Denmark, 2007, p. 129-134. Disponível em: <http://natmus.dk/fileadmin/ user_upload/natmus/bevaringsafdelingen/billeder/M_M/Museum_Microclimate/Proceedings/ poster-bog-150.pdf>. Acesso em: 9 set. 2016.

CAMUFFO, Dario. Microclimate for Cultural Heritage. Amsterdam: Elsevier, 1998.

CAPPITELLI, Francesca; FERMO, Paola; VECCHI, Roberta; PIAZZALUNGA, Andrea; VALLI, Gianluigi; ZANARDINI, Elisabetta; SORLINI, Claudia. Chemical-physical and Microbiological Measurements for Indoor Air Quality Assessment at the Ca' Granda Historical Archive. Water, Air, and Soil Pollution, vol. 201, p. 109-120, 2009.

CARATELLI, Alessia; SIANI, Anna Maria; ROCCO CASALE, Giuseppe; PARAVICINI, Alessandro; HERMANN FIORE, Kristina; CAMUFFO, Dario. Stucco panels of Room VI in the Galleria Borghese (Rome): Physical-chemical analysis and microclimate characterization. Energy and Buildings, v. 61, p. 133-139, jun. 2013.

CASS, Glenn; NAZAROFF, William; TILLER, Christine; WHITMORE, Paul. Protection of works of art from damage due to atmospheric ozone. Atmospheric Environment, v. 25, p. 441-451, 1991.

DRUZIK, James; GROSJEAN, Daniel; NAZAROFF, William; WHITMORE, Paul; WITTMAN, Cynthia. Protection of Works of Art from Atmospheric Ozone. Los Angeles: The Getty Conservation Institute, 1989. Disponível em: <https://www.getty.edu/conservation/ publications_resources/pdf_publications/pdf/ozone.pdf>. Acesso em: 9 set. 2016.

CASSAR, May; HUTCHINGS, Jeremy. Relative Humidity and Temperature Pattern Book $-a$ guide to understanding and using data on the museum environment. Londres: Museums \& Galleries Commission, 2000. Disponível em: <http://www.ucl.ac.uk/sustainableheritage-save/ RH_pattern_book.pdf>. Acesso 8 ago. 2017.

Environmental Management. Londres: Routledge, 1994.

CAVICCHIOLI, Andréa; SOUZA, Ravi Orsini Camargo de; REIS, Guilherme Ranieri. Indoor Ozone and Nitrogen Dioxide Concentration in Two Museums of the São Paulo Megacity Brazil. E-Preservation Science, v. 10, p. 114-122, 2013. Disponível em: <http://www.moranartd.com/e-preservationscience/2013/Cavicchioli-18.pdf>. Acesso em: 9 set. 2016.

CETESB - Companhia Ambiental do Estado de São Paulo. Desenvolvida pela Secretaria do Meio Ambiente do Estado de São Paulo. Apresenta o sistema QUALAR. Disponível em: <http:// ar.cetesb.sp.gov.br/qualar/>. Acesso em: 9 nov. 2017. 
CHAPUIS, Michel; LYDON, Adèle; BRANDT-GRAU, Astrid. Preserving our Heritage, Improving our Environment: Volume II - Cultural Heritage Research: FP5, FP6 and Related Projects. Luxembourg: Publications Office of the European Union, 2009, p. 33-248. Disponível em: <http://www.eurosfaire.prd.fr/7pc/doc/1263283040_20years_cultural_heritage_vol2_en.pdf >. Acesso em: 9 set. 2016.

CHIAVARI, Cristina; MARTINI, Carla; PRANDSTRALlER, Daria; NIKLASSON, Annika; JOHANSSON, Lars-Gunnar; SVENSSON, Jan-Erik; ÅSLUND, Alf; BERGSTENC, Carl Johan. Atmospheric corrosion of historical organ pipes: The influence of environment and materials. Corrosion Science, v. 50, p. 2444-2455, 2008.

CHILD, Robert. Insect damage as a function of climate. In: PADFIELD, Tim; BORCHERSEN, Karen (Ed.). Contributions to the Copenhagen Conference Museum microclimates. Copenhagen: The National Museum of Denmark, 2007, p. 57-60. Disponível em: <http://natmus.dk/ fileadmin/user_upload/natmus/bevaringsafdelingen/billeder/M_M/Museum_Microclimate/ Proceedings/poster-bog-150.pdf>. Acesso em: 9 set. 2016.

CLARK, Robin; GIBBS, Peter. Raman microscopy of a 13-th century illuminated text. Analytical Chemistry, v. 70, p. 99A-104A, 1998.

COLOMBINI, Maria Perla; ANDREOTTI, Alessia; BONADUCE, Ilaria; MODUGNO, Francesca; RIBECHINI, Erika. Analytical strategies for characterising organic paint media using GC-MS. Accounts of Chemical Research, v. 395, p. 715-727, 2010.

CORGNATI, Stefano Paolo; FABI, Valentina; FILIPPI, Marco. A methodology for microclimatic quality evaluation in museums: Application to a temporary exhibit. Building and Environment, v. 44, p. 1253-1260, 2009.

DE LA RIE, René. Old master paintings: a study of the varnish problem. Analytical Chemistry, v. 61 , p. $1228-1240,1989$.

DOMÉNECH-CARBÓ, Antonio. Voltammetric methods applied to identification, speciation, and quantification of analytes from works of art: an overview. Journal of Solid State Electrochemistry, v. 14, p. 363-379, 2010.

DRUZIK, James; ESHØJ, Bent. Museum lighting: its past and future development. In: PADFIELD, Tim; BORCHERSEN, Karen (Ed.). Contributions to the Copenhagen Conference Museum Microclimates. Copenhagen: The National Museum of Denmark, 2007, p. 51-56. Disponível em: <http://natmus.dk/fileadmin/user_upload/natmus/bevaringsafdelingen/ billeder/M_M/Museum_Microclimate/Proceedings/poster-bog-150.pdf>. Acesso em 9 set. 2016. 
FARIA, Dalva Lúcia Araújo de; PUGLIERI, Thiago Sevilhano. Metal corrosion in polychrome baroque lead sculptures: a case study. Journal of the Brazilian Chemical Society, São Paulo, v. 24, n. 8, p. 1345-1350, 2013. Disponível em: <http://www.scielo.br/scielo.php?script=sci_ar ttext\&pid=S0103-50532013000800016>. Acesso em: 9 set. 2016.

FELLER, Robert. Accelerated Aging Photochemical and Thermal Aspects. Los Angeles: The J. Paul Getty Trust, 1994. Disponível em: <http://www.getty.edu/conservation/publications_ resources/pdf_publications/pdf/aging.pdf>. Acesso em: 9 set. 2016.

Control of deteriorating effects of light upon museum objects. Museum, v. 17, p. 57$105,1964$.

FENGXIANG, Che; QINGXUANG, Hu; ZHENSHENG, Chen; LINGYIN, Meng; SHIGANG, Yan. Factors of influence on microbial pollution in the atmosphere over Beijing area. Aerobiologia, v. 7, p. 136-143, 1991.

GIBSON, Lorraine; COOKSEY, Brian; LITTLEJOHN, David; TENNENT, Norman. Investigation of the composition of a unique efflorescence on calcareous museum artifacts. Analytica Chimica Acta, v. 337, p. 253-264, 1997.

GONÇALVES, Willi de Barros. Métricas de preservação e simulações computacionais como ferramentas diagnósticas para a conservação preventiva de coleções: estudo de caso no sítio patrimônio mundial de Congonhas - MG. Tese (Doutorado) - Escola de Belas Artes, Universidade Federal de Minas Gerais, Belo Horizonte, 2013.

GRAEDEL, Thomas; MCGILL, Ron. Degradation of materials in the atmosphere. Environmental Science E Technology, v. 20, p. 1093-1099, 1986.

GRAU-BOVÉ, Josep; STRLIC, Matija. Fine particulate matter in indoor cultural heritage: a literature review. Heritage Science, v. 1:8. Disponível em: <https://heritagesciencejournal. springeropen.com/articles/10.1186/2050-7445-1-8>. Acesso em: 15 nov. 2017.

GRONTOFT, Terje; ODLYHA, Marianne; MOTTNER, Peter; DAHLIN, Elin; LÓPEZ-APARICIO, Susana; JAKIELA, Slawomir; SCHARFF, Mikkel; ANDRADE, Guillermo; OBARZANOWSKI, Michal; RYHL-SVENDSEN, Morten; THICKETT, David; HACKNEY, Stephen; WADUM, Jørgen. Pollution monitoring by dosimetry and passive diffusion sampling for evaluation of environmental conditions for paintings in microclimate frames. Journal of Cultural Heritage, v. 11, p. 411-419, 2010.

GRZYWACZ, Cecily. GCI Pollution Research: what we wave learned and where do we go from here?. Glasgow, 1998. Disponível em: <http://iaq.dk/iap/iap1998/1998_08.htm>. Acesso em 9 set. 2016. 
Monitoring for Gaseous Pollutants in Museum Environments. Los Angeles: The Getty Conservation Institute, 2006.

; TENNENT, Norman. Pollution monitoring in storage and display cabinets: carbonyl pollution in relation to artefact deterioration. In: PREPRINTS OF THE CONTRIBUTIONS TO THE OTTAWA CONGRESS, IIC, 1994, Ottawa. ROY, Ashok; SMITH, Perry (Ed.). Preventive Conservation Practice, Theory and Research. Londres: Archetype Publications, 1994.

GYSELS, Kristin; DELALIEUX, Filip; DEUTSCH, Felix; VAN GRIEKEN, René; CAMUFFO, Dario; BERNARDI, Adriana; STURARO, Giovanni; BUSSE, Hans-Jürgen; WIESER, Monika. Indoor environment and conservation in the Royal Museum of Fine Arts, Antwerp, Belgium. Journal of Cultural Heritage, v. 5, p. 221-230, 2004.

HARTMANN, Dennis; KLEIN TANK, Albert; RUSTICUCCI, Matilde; ALEXANDER, Lisa; BRÖNNIMANN, Stefan; CHARABI, Yassine; DENTENER, Frank; DLUGOKENCKY, Edward; EASTERLING, David; KAPLAN, Alexey; SODEN, Brian; THORNE, Peter; WILD, Martin; ZHAI, Panmao. Observations: atmosphere and surface. In: INTERGOVERNMENTAL PANEL ON CLIMATE CHANGE. Climate Change 2013: The Physical Science Basis. Contribution of Working Group I to the Fifth Assessment Report of the Intergovernmental Panel on Climate Change. Cambridge: Cambridge University Press, 2013, p. 159-254. Disponível em: <http:// www.climatechange2013.org/report/full-report/>. Acesso em: 9 set. 2016.

HATCHFIELD, Pamela. Pollutants in the Museum Environment: practical strategies for problem solving, exhibition and storage. Londres: Archetype Publications, 2002.

LEVIN, Jeffrey. Preventive conservation. Conservation Perspectives, Los Angeles: The Getty Conservation Institute, Newsletter 7.1, 1992.

LÓPEZ-APARICIO, Susana; GRØNTOFT, Terje; ODLYHA, Marianne; SCHARFF, Mikkel. Measurement of organic and inorganic pollutants in microclimate frames for paintings. E-Preservation Science, v. 7, p. 59-70, 2010.

LOURENÇO, Maria Cecília França (org.). A Casa de Dona Yayá. São Paulo: Edusp, 2001.

MICHALSKI, Stefan. A decisão sobre a iluminação. In: MENDES, Marylka; SILVEIRA, Luciana da; BEVILAQUA, Fátima; BAPTISTA, Antonio Carlos Nunes (Ed.). Conservação: conceitos e práticas. Rio de Janeiro: Editora UFRJ, 2001.

Care and preservation of collections. In: BOYLANB, Patrick (Ed.). Running a Museum:

A Practical Handbook. Paris: International Council of Museums \& Unesco, 2004, p. 51-90. 
Double the life for each five-degree drop, more than double the life for each halving of relative humidity. In: PREPRINTS OF THE ICOM COMMITTEE FOR CONSERVATION, 13, 2002, Rio de Janeiro. Anais... Londres: James \& James, 2002. Disponível em: <https://cci-iccgc.academia.edu/StefanMichalski>. Acesso em: 9 set. 2016.

Paintings - their response to temperature, relative humidity, shock and vibration. In: MECKLEBURG, Marion (Ed.). Art in Transit: Studies in the Transport of Paintings. Washington: National Gallery of Art, 1991, p. 223-249. Disponível em: <https://repository.si.edu/ handle/10088/8128>. Acesso em: 9 set. 2016.

The power of history in the analysis of collection risks from climate fluctuations and light. In: PREPRINTS OF THE ICOM COMMITTEE FOR CONSERVATION, 17, 2014, Melbourne. Anais... Paris: The International Council of Museums, 2014. Disponível em: <https://www. academia.edu/11941527/2014._The_Power_of_History_in_the_Analysis_of_Collection_Risks_ from_Climate_Fluctuations_and_Light>. Acesso em: 9 set. 2016.

MONICO, Letizia; VAN DER SNICKT, Geert; JANSSENS, Koen; DE NOLF, Wout; MILIANI, Costanza; DIK, Joris; RADEPONT, Marie; HENDRIKS, Ella; GELDOF, Muriel; COTTE, Marine. Degradation process of lead chromate in paintings by Vincent van Gogh studied by means of synchrotron X-ray spectromicroscopy and related methods: Artificially aged model samples. Analytical Chemistry, v. 83, n. 1, p. 1214-1223, 2011.

MORTON, Leslie; SURMAN, Susanne. Biofilms in biodeterioration - a review. International Biodeterioration \& Biodegradation, v. 34, p. 203-221, 1994.

NAZAROFF, William; LIGOCKI, Mary; SALMON, Lynn; CASS, Glen; FALL, Theresa; JONES, Michael; LIU, Harvey; MA, Timothy. Airborne Particles in Museums. Marina del Rey: The Getty Conservation Institute, 1993. Disponível em: < http://www.getty.edu/conservation/ publications_resources/pdf_publications/airborne_particles.html>. Acesso em: 9 set. 2016.

NIKLASSON, Annika; LANGER, Sarka; ARRHENIUS, Karine; ROSELL, Lars; BERGSTEN, Carl Johan; JOHANSSON, Lars-Gunnar; SVENSSON, Jan-Erik. Air Pollutant Concentrations and Atmospheric Corrosion of Organ Pipes in European Church Environments. Studies in Conservation, v. 53, p. 24-40, 2008.

NUSSBAUM, Francis. Variation in the airborne fungal spore population of the Tuscarawas Valley II. A comparison of arboreal and nonarboreal microenvironments. Mycopathologia, v. 116, p. 181-198, 1991.

ODLYHA, Marianne. The applications of thermoanalytical techniques to the preservation of art and archaeological objects. In: BROWN, Michael; GALLAGHER, Patrick (Ed.). Handbook of Thermal Analysis and Calorimetry. Amsterdam: Elsevier, 2003, p. 47-96. 
PADFIELD, Tim. Conservation Physics: Sensors, Measurement and Data Handling. [s.n.t.]. Disponível em: <http://www.conservationphysics.org/>. Acesso em: 24 jul. 2017.

; ERHARD, David; HOPWOOD, Walter. Trouble in store. In: PREPRINTS OF THE CONTRIBUTIONS TO THE WASHINGTON D.C. CONGRESS, 1982, Washington D.C. BROMMELLE, Norman; THOMSON, Garry. Science and Technology in the Service of Conservation. Londres: International Institute for Conservation of Historic and Artistic Works, 1982.

PASQUARELLA, Cesira; SACCANI, Elisa; SANSEBASTIANO, Giuliano; ALBERTINI, Roberto. Proposal for a biological environmental monitoring approach to be used in libraries and archives. Annals of Agricultural and Environmental Medicine, v. 19, p. 209-212, 2012.

RIMMER, Melanie; THICKETT, David; WATKINSON, David; GANIARIS, Helen. Guidelines for the Storage and Display of Archaeological Metalwork. Swindon: English Heritage, 2013.

SCHAEFFER, Terry. Effects of Light on Materials in Collections: data on photoflash and related sources. Los Angeles: The J. Paul Getty Trust, 2001.

SCHIEWECK, Alexandra, et al. Occurrence of organic and inorganic biocides in the museum environment. Atmospheric Environment, v. 41, p. 3266-3275, 2007.

et al. Organic and inorganic pollutants in storage rooms of the Lower Saxony State Museum Hanover. Atmospheric Environment, v. 39, p. 6098-6108, 2005.

; SALTHAMMER, Tunga. Emissions from Construction and Decoration Materials for Museum Showcases. Studies in Conservation, v. 54, p. 218-235, 2009.

SEBERA, Donald. A graphical representation of the relationship of environmental conditions to the permanence of hygroscopic materials and composites. In: PROCEEDINGS OF CONSERVATIONS IN ARCHIVES: INTERNATIONAL SYMPOSIUM OF CONSERVATION IN ARCHIVES, 1988, Ottawa. Anais... Paris: International Council on Archives, 1988.

SHAVER, Cynthia; CASS, Glenn; DRUZIK, James. Ozone and the deterioration of works of art. Environmental Science \& Technology, v. 17, p. 748-752, 1983.

SKORA, Justyna; GUTAROWSKA, Beata; PIELECH-PRZYBYLSKA, Katarzyna; ST囚PIE区, Łukasz; PIETRZAK, Katarzyna; PIOTROWSKA, Małgorzata; PIETROWSKI, Piotr. Assessment of microbiological contamination in the work environments of museums, archives and libraries. Aerobiologia, v. 31, n. 3, p. 389-401, 2015. 
SPOLNIK, Zoya; WOROBIEC, Anna; INJUK, Jasna; NEILEN, Dionne; SCHELLEN, Henk; VAN GRIEKEN, Réne. Chemical Characterization of Airborne Particles in St. Martinus Cathedral in Weert, The Netherlands. Microchimica Acta, v. 145, p. 223-227, 2004.

STABILE, Luca; FUOCO, Fernanda; BUONANNO, Giorgio. Characteristics of particles and black carbon emitted by combustion of incenses, candles and anti-mosquito products. Building and Environment, v. 56, p. 184-191, oct. 2012.

TÉTREAUlT, Jean. Airborne Pollutants in Museums, Galleries, and Archives: Risk Assessment, Control Strategies, and Preservation management. Ottawa: Canadian Conservation Institute, 2003.

THOMSON, Garry. The Museum Environment. Oxford: Butterworth-Heinemann, 1986.

TOLEDO, Franciza Lima. The role of architecture in preventive conservation. Rome: ICCROM, 2006. Disponível em: <http://www.iccrom.org/ifrcdn/pdf/ICCROM_13_ArchitPrevenConserv_ en.pdf>. Acesso em: 9 set. 2016.

TRENTELMAN, Karen; STODULSKI, Leon. Characterization of Pararealgar and Other LightInduced Transformation Products from Realgar by Raman Microspectroscopy. Analytical Chemistry, v. 68, p. 1755-1761, 1996.

VAN DEN BRINK, Oscar; EIJKEL, Gert; BOON, Jaap. Dosimetry of paintings: determination of the degree of chemical change in museum-exposed test paintings by mass spectrometry. Thermochimica Acta, v. 365, p. 1-23, 2000.

VAN-GRIEKEN, René; JANSSENS, Koen. Cultural Heritage Conservation and Environmental Impact Assessment by Non-Destructive Testing and Micro-Analysis. Londres: Taylor \& Francis, 2005.

VANDENABEELE, Peter; EDWARDS, Howell; JEHLOCKA, Jan. The role of mobile instrumentation in novel applications of Raman spectroscopy: archaeometry, geosciences, and forensics. Chemical Society Reviews, v. 43, n. 8, p. 2628-2649, 2014.

VIITANEN, Hannu; VINHA, Juha; SALMINEN, Kati; OJANEN, Tuomo; PEUHKURI, Ruut; PAAJANEN, Leena; LÄHDESMÄKI, Kimmo. Moisture and bio-deterioration risk of building materials and structures. Journal of Building Physics, v. 33, p. 201-224, 2010.

WALLER, Robert. A risk model for collection preservation. In: VONTOBEL, Roy; ICOM Committee for Conservation (Ed.). Thirteen Triennial Meeting of the ICOM Committee for Conservation. Londres: James and James, 2002, p. 102-107. 
WHITMORE, Paul; CASS, Glenn. The ozone fading of traditional Japanese colorants. Studies in Conservation, v. 33, p. 29-40. 1988.

; DRUZIK, James. Ozone fading of traditional natural organic colorants on paper. Journal of the American Institute for Conservation, v. 26, p. 45-48, 1987.

Artigo apresentado em 19/09/2016. Aprovado em 18/08/2017.

\section{(c) BY}

